\title{
Algorithm Development for the Optimum Rainfall Estimation Using Polarimetric Variables in Korea
}

\author{
Cheol-Hwan You ${ }^{1}$ and Dong-In Lee ${ }^{2}$ \\ ${ }^{1}$ Atmospheric Environmental Research Institute, Pukyong National University, Yongso-ro, Nam-gu, Busan 608-737, Republic of Korea \\ ${ }^{2}$ Department of Environmental Atmospheric Sciences, Pukyong National University, Yongso-ro, Nam-gu, \\ Busan 608-737, Republic of Korea
}

Correspondence should be addressed to Dong-In Lee; leedi@pknu.ac.kr

Received 17 October 2014; Accepted 3 May 2015

Academic Editor: Anthony R. Lupo

Copyright ( $\odot 2015$ C.-H. You and D.-I. Lee. This is an open access article distributed under the Creative Commons Attribution License, which permits unrestricted use, distribution, and reproduction in any medium, provided the original work is properly cited.

In this study, to get an optimum rainfall estimation using polarimetric variables observed from Bislsan radar which is the first polarimetric radar in Korea, rainfall cases for 84 hours caused by different conditions, which are Changma front and typhoon, Changma front only, and typhoon only, occurred in 2011, were analyzed. And rainfall algorithms were developed by using long period drop size distributions with six different raindrop axis ratio relations. The combination of the relations between $R$ and $Z$, $Z_{\mathrm{DR}}, R$ and $K_{\mathrm{DP}}, Z_{\mathrm{DR}}$, and $R$ and $K_{\mathrm{DP}}$ with different rainfall intensity would be an optimum rainfall algorithm if the reference of rainfall would be defined correctly. In the case the reference is not defined adequately, the relation between $R$ and $Z, Z_{\mathrm{DR}}, K_{\mathrm{DP}}, A_{H}$ and $R$ and $Z, K_{\mathrm{DP}}, A_{H}$ can be used as a representative rainfall relation. Particularly if the qualified $Z_{\mathrm{DR}}$ is not available, the relation between $R$ and $Z, K_{\mathrm{DP}}, A_{H}$ can be used as an optimum rainfall relation in Korea.

\section{Introduction}

Measurement of drop size distributions (DSDs) have been extensively used to calculate both radar reflectivity and rain rate for conventional radar and there is no unique relation between horizontal reflectivity $(Z)$ and rain rate $(R)$ (hereinafter $R(Z)$ ) in the world because DSDs could vary from storm to storm and within the storm itself $[1,2]$. Calculations of polarimetric parameters such as $Z$, differential reflectivity $\left(Z_{\mathrm{DR}}\right)$, differential phase shift $\left(\Phi_{\mathrm{DP}}\right)$, cross correlation coefficients $\left(\rho_{h v}\right)$, specific differential phase $\left(K_{\mathrm{DP}}\right)$, and specific attenuation $\left(A_{H}\right)$ could be obtained using T-matrix scattering techniques derived by Waterman [3] and later developed further by Mishchenko et al. [4]. The raindrop axis is one of the parameters for calculating polarimetric variables of T-matrix simulation. The variations of raindrop axis ratio in nature are intensively related to the oscillating of raindrop and hence are also connected to the polarimetric variables. There are many researches on the investigation of raindrop shape by laboratory study $[5,6]$, field measurements $[7,8]$, and modeling $[9,10]$.
Many researchers noticed that radar rainfall estimation is contaminated by a number of uncertainties such as hardware calibration, partial beam filling, rain attenuation, and nonweather echoes [11, 12]. To mitigate these problems, the particle identification algorithm using polarimetric parameters for improving data quality control and rainfall estimates by the discrimination of nonmeteorological artifacts such as anomalous propagation, birds, insects, and second trip echo was developed [13-15]. And improvement of quantitative precipitation estimation (QPE) accuracy is one of the major points of polarization radar [16-20]. Ryzhkov et al. [21] compared the rainfall relations with different drop shape assumptions and developed rainfall algorithm using polarimetric radar for the prototype WSR-88D. Cifelli et al. [22] compared the two rainfall algorithms, CSU-HIDRO (Colorado State University-Hydrometeor IDentification of Rainfall) and JPOLE- (Joint Polarization Experiment-) like, in the high plains environment. Recently, Ryzhkov et al. [23] investigated the potential utilization of $A_{H}$ for rainfall estimation using $\mathrm{X}$-band and S-band radar. They found that $R(A)$ method 


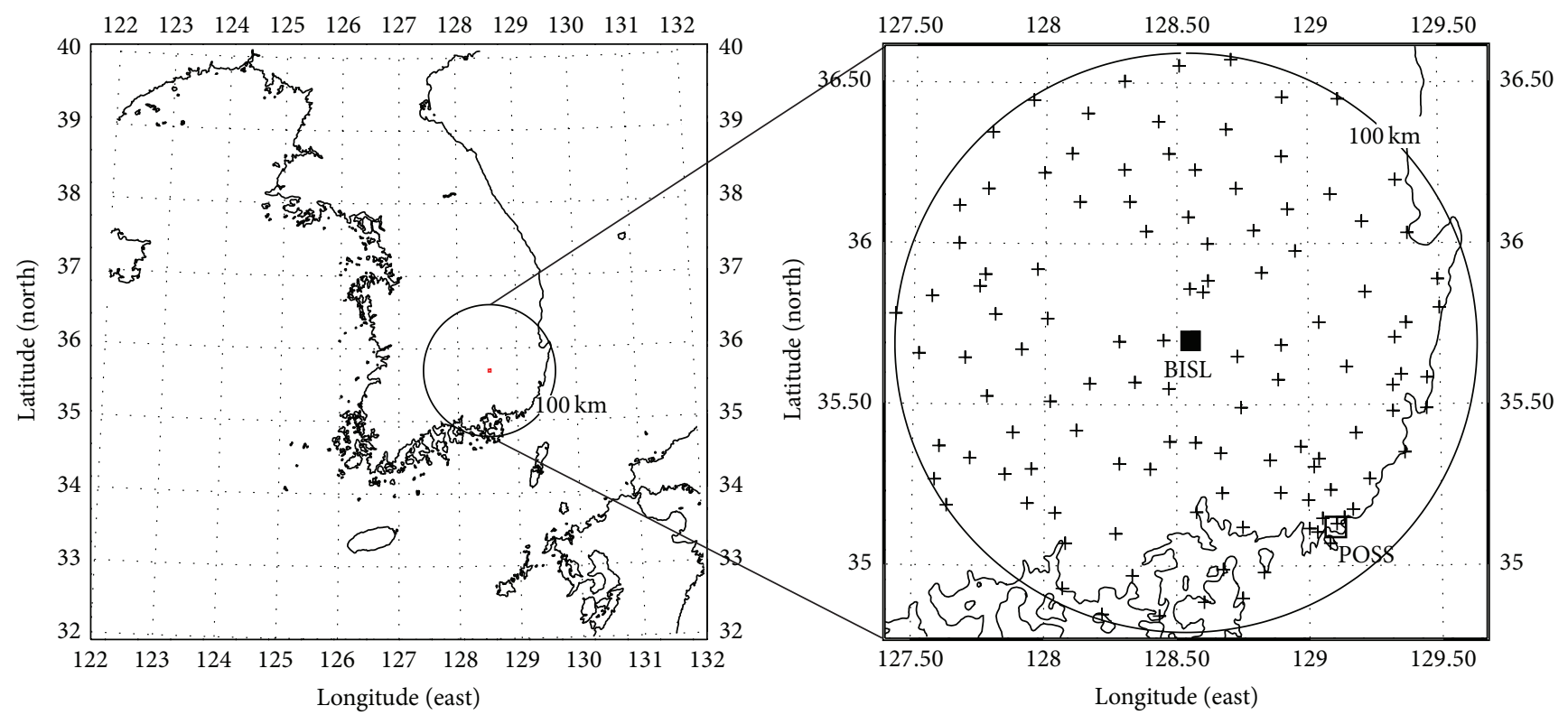

FIGURE 1: The location of a Bislsan radar (solid rectangle), a POSS disdrometer (open rectangle), and rain gages (plus sign) distributed within $100 \mathrm{~km}$ of radar coverage.

yields robust estimates of rain rates and rain totals even at $\mathrm{S}$ band which has very small attenuation.

There have been also many researches on polarimetric radar to implement it into operational uses. Based on these theoretical and other experimental researches, many countries are replacing or modifying their radars into polarimetric radar for operational use. There are three major agencies, Ministry of National Defense (MND), Ministry of Land, Infrastructure and Transportation (MOLIT), and Korea Meteorological Administration (KMA), which operate radars to monitor and forecast severe weather and flash flood operationally in Korea. Among these agencies, MOLIT installed polarimetric radars in 2009 and 2012 for the first time in Korea. KMA has installed the S-band polarimetric radar at the most northwestern part of Korea in 2014. For successful implementation of their radars for the purpose of operational uses, many researches on rainfall estimation, hydrometeor classification, and DSDs retrieval are required. However, there are few studies on these polarimetric related issues except for getting relationships using long period disdrometer data and assessment of each relation after applying a very simple quality control for differential phase shift [24]. They found that the accuracy of rainfall estimation using $R\left(Z, Z_{\mathrm{DR}}\right)$ obtained by DSDs of Busan area in Korea was the best one comparing with relations calculated by ones of Oklahoma in US. And the quality control and unfolding of $\Phi_{\mathrm{DP}}$ for calculating $K_{\mathrm{DP}}$ were applied to the rainfall estimation [25]. The above two studies used only 84,574 samples of DSDs excluding winter rainfall events, two and four raindrop shapes for calculation of rainfall relations.

This paper discussed how to improve the accuracy of the rainfall estimation using all polarimetric variables with different raindrop shapes and get optimum rainfall algorithm for Korean S-band polarimetric radar. In Section 2, rain gage,
DSDs and radar dataset, calculation of rainfall relations, raindrop axis ratio relations, and the method of validation are described. Section 3 provides the optimum rainfall algorithms with and without rainfall category followed by the calculation of $A_{H}$ using observed $\Phi_{\mathrm{DP}}$ and $Z$ and the validations of rainfall estimation. Finally, we provide some conclusions and derived results are summarized in Section 4.

\section{Data and Methodology}

2.1. Rain Gage and Radar Dataset. The rainfall data from rain gages operated by the KMA were used to evaluate the accuracy of radar rainfall. Rain gages located from $5 \mathrm{~km}$ to $95 \mathrm{~km}$ within radar coverage are included in the analysis. Figure 1 shows the location of all instruments used in this study. The circle means the radar coverage, solid rectangle is the center of Bislsan radar, plus sign shows the distributed rain gages within radar coverage, and open rectangle is the location of a POSS (Precipitation Occurrence Sensor System) disdrometer that was installed around $82 \mathrm{~km}$ away from radar.

Radar data were collected by Bislsan polarimetric radar that was installed and operated by MOLIT in Korea since 2009. The specifications of Bislsan polarimetric radar and the quality control algorithm of $\Phi_{\mathrm{DP}}$ were shown by You et al. $[24,25]$.

\subsection{Calculations of Polarimetric Variables and Validation.}

The relations for converting radar variables into rain rate are required to get rainfall because radar could not observe the rainfall directly. In order to calculate these relations, disdrometer data which can measure the DSDs are needed. Oneminute DSDs obtained by POSS (Precipitation Occurrence Sensor System) from 2001 to 2004 were used and processed to remove the unreliable data as shown by You et al. [25]. 


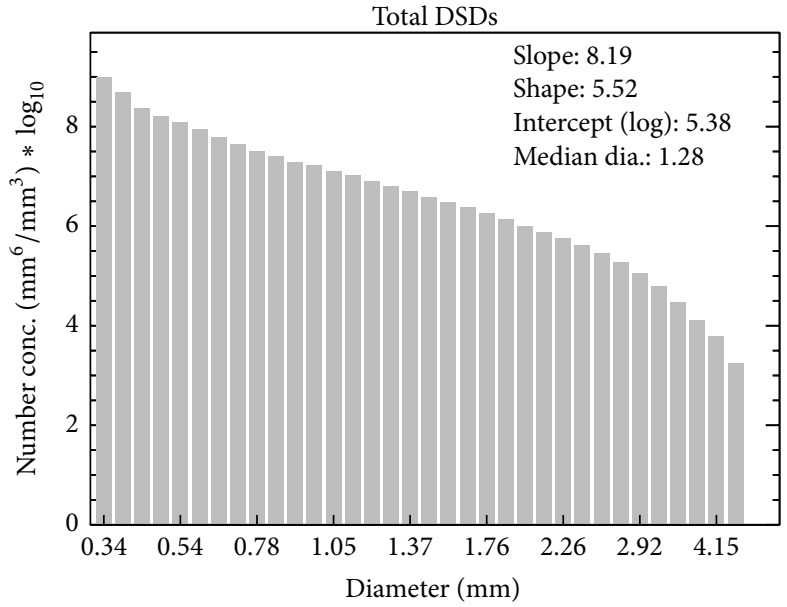

(a)

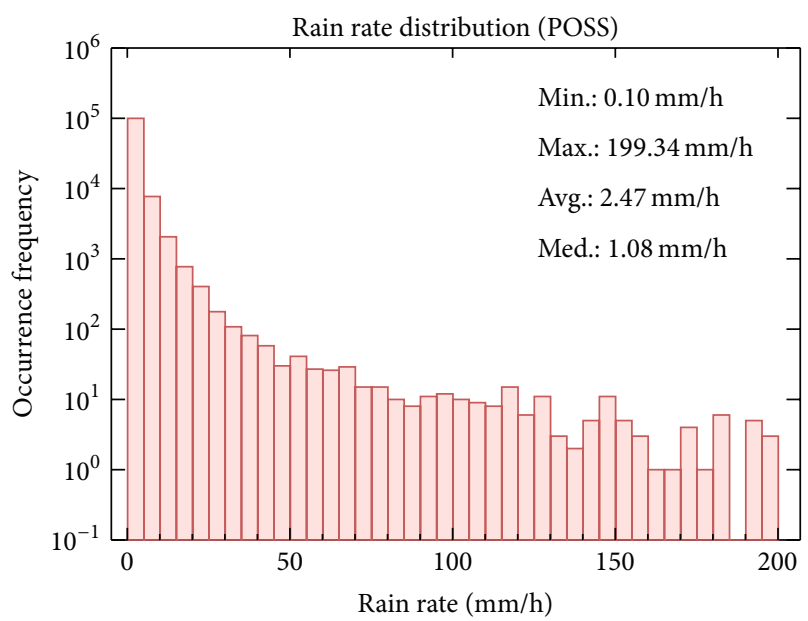

(b)

FIGURE 2: Histogram of (a) total number concentration with respect to the drop size and gamma parameters and (b) rain rate calculated using 114,105 samples of 1-minute DSD after quality control.

DSDs data for calculations of relationships were 114,105 samples after quality control and removal of negative $K_{\mathrm{DP}}$. The total number concentration with respect to the drop size and the averaged parameters of gamma distributions was shown in Figure 2(a). The slope, shape, and intercept for gamma model were $8.2,5.5$, and $10^{5.4}$, respectively, and median diameter was $1.3 \mathrm{~mm}$. Most of the data are distributed in a wide range with a maximum rain rate of about $199.3 \mathrm{~mm} \mathrm{~h}^{-1}$ and the average was $2.47 \mathrm{~mm} \mathrm{~h}^{-1}$ (Figure 2(b)).

Polarimetric variables were calculated using T-matrix scattering techniques derived by Waterman [3] and later developed further by Mishchenko et al. [4]. To get the variables using DSDs, six raindrop shape assumptions are used.

The first raindrop axis ratio used in this study has slightly modified the relation proposed by Pruppacher and Beard [5] and will be called DS1:

$$
\frac{b}{a}= \begin{cases}1.0 & 0 \leq D \leq 0.3 \mathrm{~mm} \\ 1.03-0.062 D & D \geq 0.3 \mathrm{~mm},\end{cases}
$$

where $a, b$, and $D$ are the major axis, minor axis, and equivolume diameter of raindrop in $\mathrm{mm}$, respectively:

$$
\begin{aligned}
\frac{b}{a}= & 1.0048+0.500057 D-0.02628 D^{2}+0.003682 D^{3} \\
& -0.0001677 D^{4} .
\end{aligned}
$$

Equation (2) is for equilibrium axis ratio derived from the numerical model of Beard and Chuang [9], which is in good agreement with the results from wind tunnel measurements (hereinafter DS2). The practical shapes of raindrops in turbulent flow are expected to be different shapes from the equilibrium shapes due to the drop oscillations. Oscillating drops appear to be more spherical on average than the drops with equilibrium shapes as shown by Andsager et al. [10] in laboratory studies. They figured out that the raindrops' shape between 1.1 and $4.4 \mathrm{~mm}$ is better explained by the following formula:

$$
\frac{b}{a}=1.012-0.01445 D-0.01028 D^{2} .
$$

Bringi et al. [26] suggested using (3) for drops with sizes smaller than $4.4 \mathrm{~mm}$ and (2) for larger sizes (hereinafter DS3). The shape-diameter relation that combines the observations of different authors was recently proposed by Brandes et al. [27, hereinafter DS4]:

$$
\begin{aligned}
\frac{b}{a}= & 0.9951+0.025 D-0.03644 D^{2}+0.005303 D^{3} \\
& -0.0002492 D^{4} .
\end{aligned}
$$

The relations of raindrop axis ratio (DS5) proposed by Beard and Kubesh [28] and Thurai et al. [29] were combined, given by

$$
\frac{b}{a}= \begin{cases}1.0 & D \leq 0.7 \mathrm{~mm} \\ 1.173-0.5165 D+0.4698 D^{2}-0.1317 D^{3}-0.0085 D^{3} & 0.7<D \leq 1.5 \mathrm{~mm} \\ 1.065-0.0625 D-0.00399 D^{2}-0.000766 D^{3}-0.0004095 D^{4} & D>1.5 \mathrm{~mm} .\end{cases}
$$


15 UTC June 24, 2011 (00 KST June 25, 2011) $90^{\circ} \mathrm{E} \quad 100^{\circ} \mathrm{E} \quad 110^{\circ} \mathrm{E} \quad 120^{\circ} \mathrm{E} \quad 130^{\circ} \mathrm{E} \quad 140^{\circ} \mathrm{E} \quad 150^{\circ} \mathrm{E} \quad 160^{\circ} \mathrm{E}$

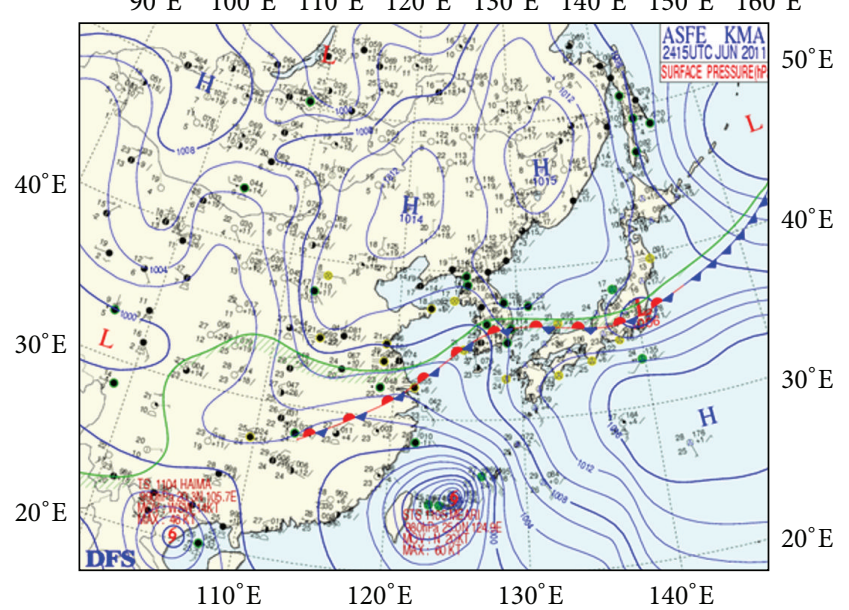

Korea Meteorological Administration (KMA)

(a)

03 UTC July 9, 2011 (12 KST July 9, 2011)

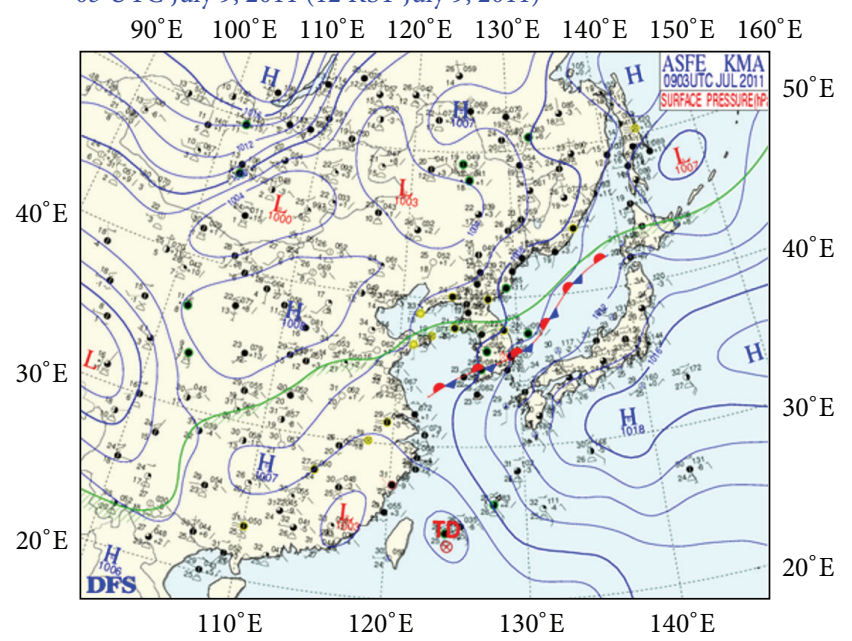

Korea Meteorological Administration (KMA)

(c)
00 UTC June 26, 2011 (09 KST June 26, 2011)

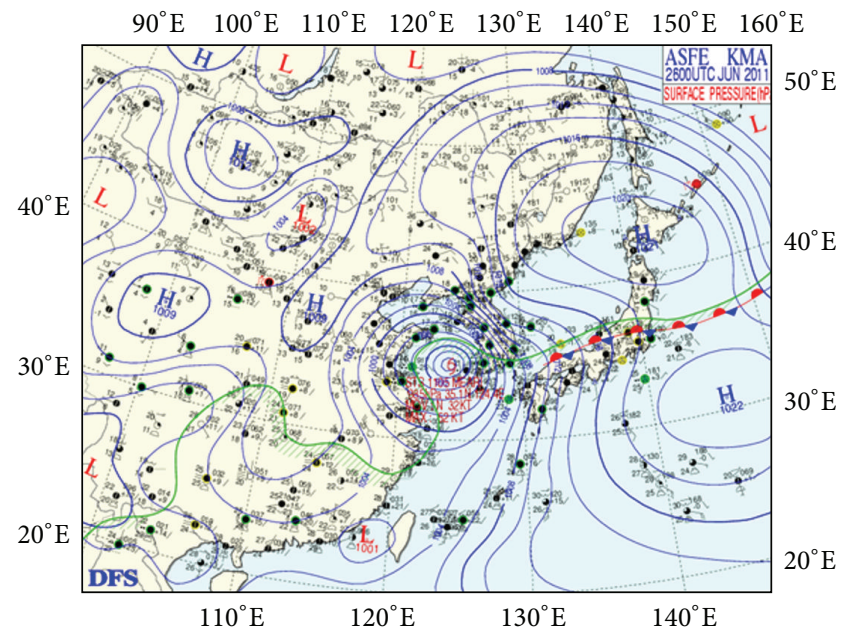

Korea Meteorological Administration (KMA)

(b)

15 UTC August 7, 2011 (00 KST August 8, 2011) $90^{\circ} \mathrm{E} \quad 100^{\circ} \mathrm{E} \quad 110^{\circ} \mathrm{E} \quad 120^{\circ} \mathrm{E} \quad 130^{\circ} \mathrm{E} \quad 140^{\circ} \mathrm{E} \quad 150^{\circ} \mathrm{E} \quad 160^{\circ} \mathrm{E}$

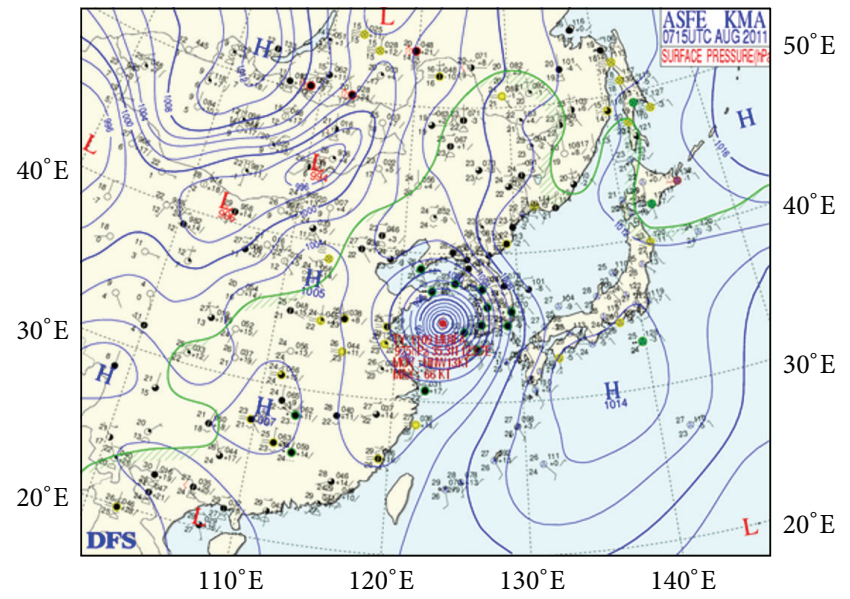

Korea Meteorological Administration (KMA)

(d)

FIgure 3: The surface weather chart (a) 0000 LST June 25, (b) 0900 LST June 26, (c), 1200 LST July 9, and (d) 0000 LST August 8 in 2011.

The relation of raindrop axis ratio that slightly modified the relation proposed by Goddard et al. [30] was used (hereinafter DS6):

$$
\begin{aligned}
& \frac{b}{a} \\
& = \begin{cases}1.0 & D \leq 1.0 \mathrm{~mm} \\
1.075-0.065 D-0.0036 D^{2}+0.0004 D^{3} & D>1.0 \mathrm{~mm} .\end{cases}
\end{aligned}
$$

Another parameter in the T-matrix calculations is the temperature, which is assumed to be $20^{\circ} \mathrm{C}$ in this study. It is also necessary to take the canting angle into consideration of the T-matrix simulation because it can account for a $6 \%$ reduction in the coefficient of the $R\left(K_{\mathrm{DP}}\right)$ relation [31] and may cause small negative biases of the estimators [32]. The distribution of canting angles of raindrops is Gaussian with a mean of $0^{\circ}$ and a standard deviation of $7^{\circ}$, which have been recently determined by Huang et al. [33].

2.3. Validations. Because the rainfall in Korea is mostly accompanied with Changma front and Typhoon, three rainfall cases, which are caused by Changma front and typhoon, Changma front only, and typhoon only, were used for validations (Table 1).

Figure 3 shows the surface weather chart of each case. The typhoon MAERI was located at the eastern ocean of Taiwan and the Changma front was elongated from eastern China continent to the central Japan through the southern part of 


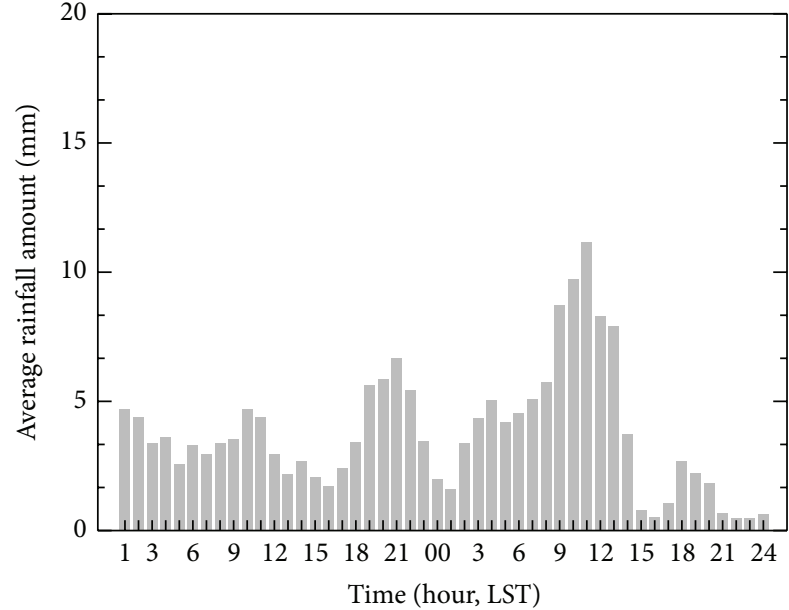

(a)

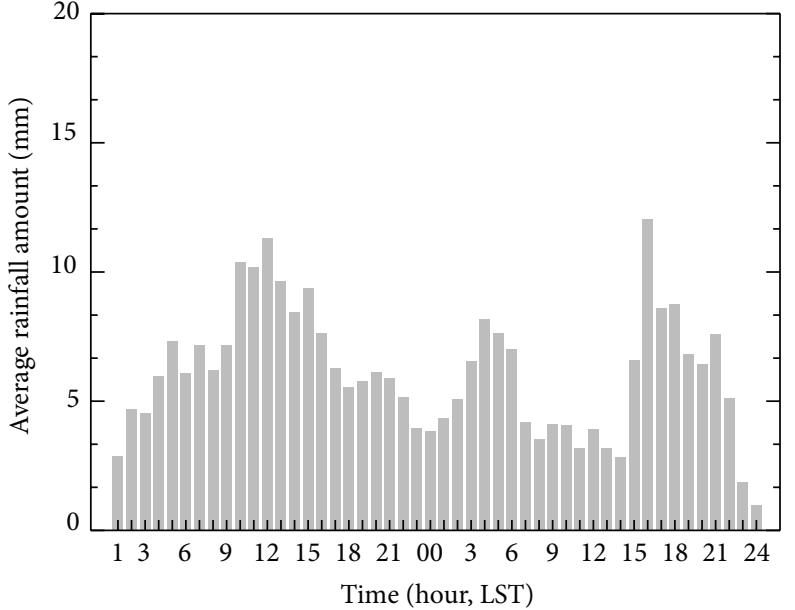

(b)

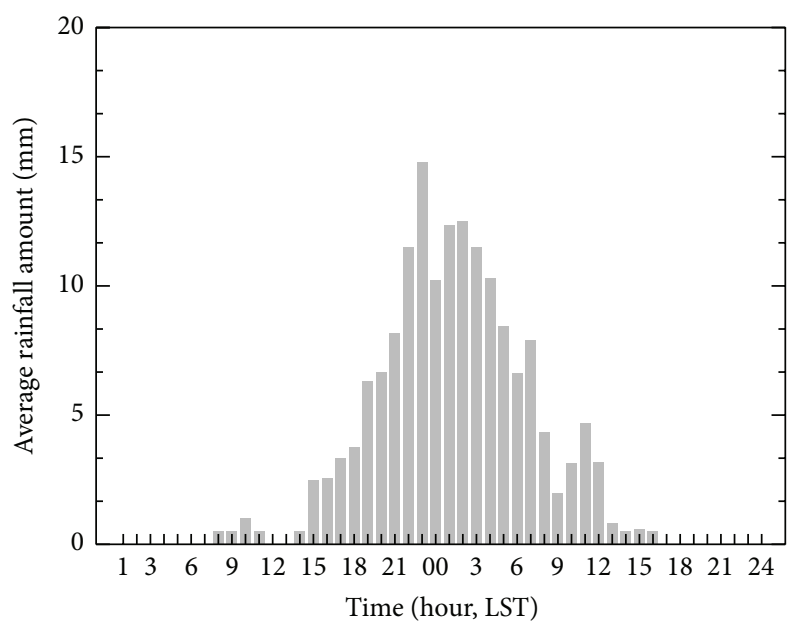

(c)

Figure 4: Time series of averaged rainfall amount, which was accompanied with (a) Changma front and typhoon, (b) Changma front only, and (c) typhoon only, averaged rainfall from all rain gages within radar coverage.

TABLE 1: Rainfall cases with different sources for the study.

\begin{tabular}{lc}
\hline Period & Sources \\
\hline 2011. 6. 25. 0900 LST 6. 26. 1400 LST & $\begin{array}{c}\text { Changma front } \\
\text { and typhoon } \\
\text { Changma front } \\
\text { 2011. 7. 09. 0000 LST 7. 10. 2200 LST }\end{array}$ \\
2011. 8. 07. 1800 LST $\sim 8.08 .0300$ LST & Typhoon \\
\hline
\end{tabular}

Korea on 0000 LST June 25 (Figure 3(a)). The MAERI moved to the north, located at the southern west sea of Korea, and made rainfall in the Korean peninsula on 0900 LST June 26 in 2011 (Figure 3(b)). Changma front was located at the southern part of Korea and brought rainfall at the analyzed area on 1200 LST July 9 in 2011 (Figure 3(c)). The rainfall was affected by Changma front all the time during case 2 . The typhoon MUIFA was located at the southwestern sea of Korea on 0000 LST August 8 in 2011 and caused rainfall at the target area (Figure 3(d)).
Figure 4 shows the time series of averaged rainfall amount observed on the ground rain gages within radar coverage from $5 \mathrm{~km}$ to $95 \mathrm{~km}$. Averaged rainfall amount refers to that obtained by averaging the amount of rainfall observed by rain gages within the radius of the radar. There are three peaks of rainfall in case of Changma front and typhoon; the first two peaks were due to Changma front and the third one was due to the influence of the typhoon. There are three peaks of rainfall accompanied with Changma front in the second rainfall event. The third event was also caused by typhoon but was relatively short. The period of the selected rainfall was 84 hours, 29 hours for Changma front and typhoon, 46 hours for Changma front only, and 9 hours for typhoon only.

The normalized error (NE), fractional root mean square error (RMSE), and correlation coefficients (CC) of rainfall relations and 121 gages were used to investigate the performance of each rainfall relation:

$$
\mathrm{NE}=\frac{(1 / N) \sum_{i=1}^{N}\left(\left|R_{R, i}-R_{G, i}\right|\right)}{\overline{R_{G}}},
$$




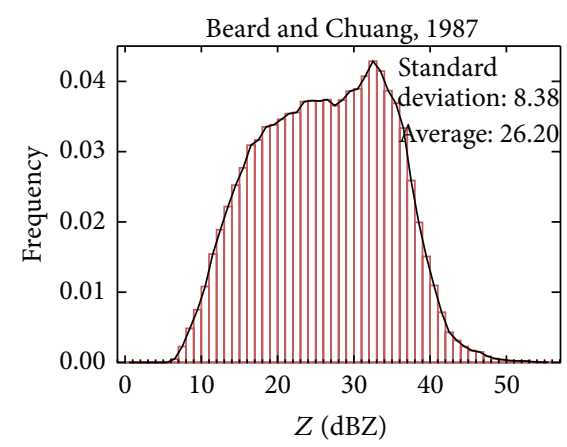

(a)

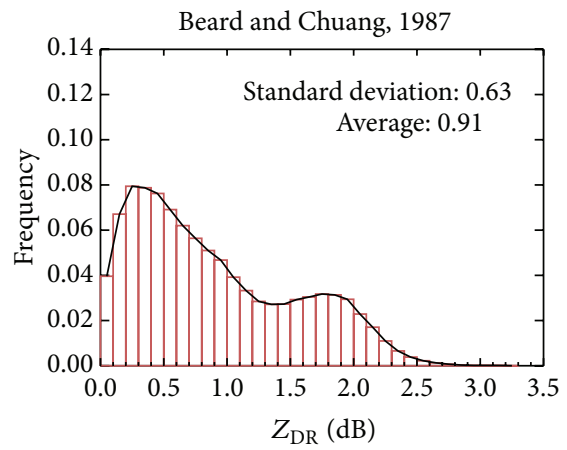

(d)

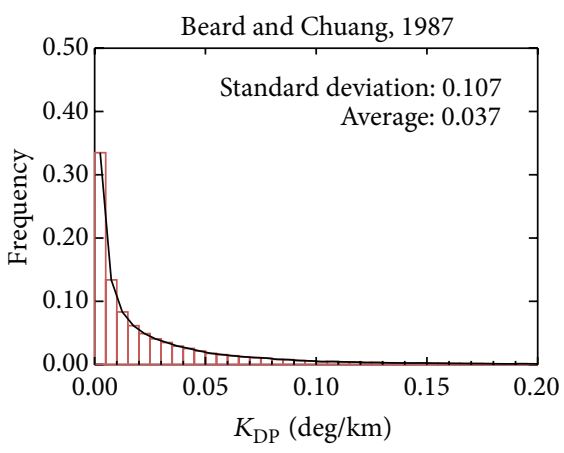

(g)

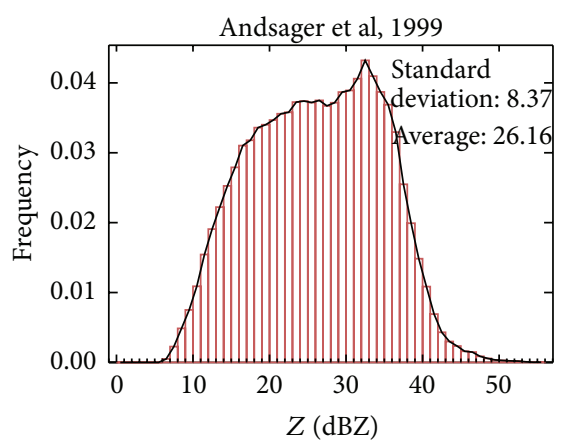

(b)

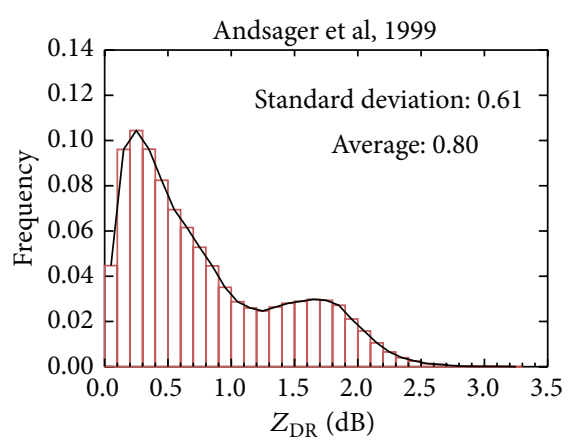

(e)

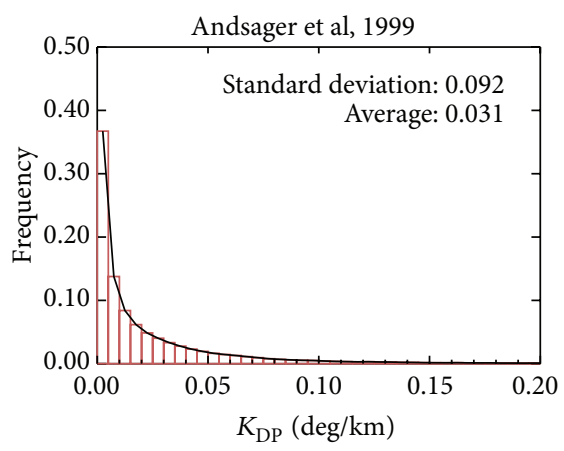

(h)

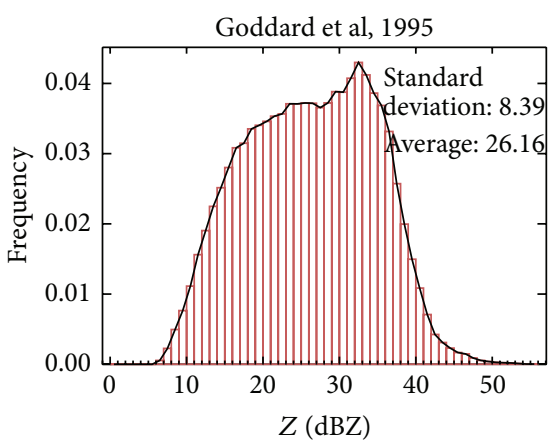

(c)

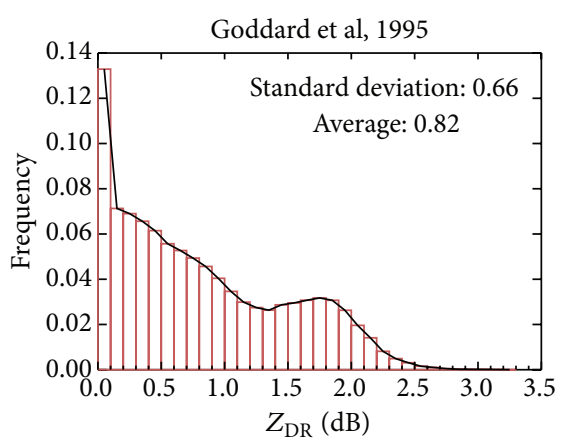

(f)

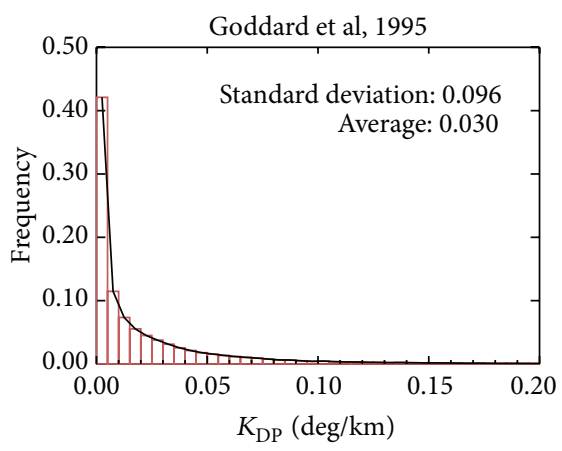

(i)

FIGURE 5: The occurrence frequency of (a) $Z$ with DS1, (b) $Z$ with DS3, (c) $Z$ with DS6, (d) $Z_{\mathrm{DR}}$ with DS1, (e) $Z_{\mathrm{DR}}$ with DS3, (f) $Z_{\mathrm{DR}}$ with DS6, (g) $K_{\mathrm{DP}}$ with DS1, (h) $K_{\mathrm{DP}}$ with DS3, and (i) $K_{\mathrm{DP}}$ with DS6.

$$
\begin{aligned}
& \mathrm{RMSE}=\left[\frac{1}{N} \sum_{i=1}^{N}\left(R_{R, i}-R_{G, i}\right)^{2}\right]^{1 / 2}, \\
& \mathrm{CC}=\frac{\sum_{i=1}^{N}\left(R_{R, i}-\overline{R_{R}}\right)\left(R_{G, i}-\overline{R_{G}}\right)}{\left[\sum_{i=1}^{N}\left(R_{R, i}-\overline{R_{R}}\right)^{2}\right]^{1 / 2}\left[\sum_{i=1}^{N}\left(R_{G, i}-\overline{R_{G}}\right)^{2}\right]^{1 / 2}},
\end{aligned}
$$

where $N$ is the number of the RR and RG pairs and $\overline{R_{R}}$ and $\overline{R_{G}}$ are the averaged rain rate of radar and gage for an hour, respectively. The above statistical variables are calculated using 1-hour rainfall amount of radar and gage at the point. The point rainfall of radar was obtained by averaging rainfall over a small area $\left(1 \mathrm{~km} \times 1^{\circ}\right)$ centered on each rain gage.

\section{Results}

\subsection{Rainfall Relations with Different Raindrop Axis Ratios}

3.1.1. The Characteristics of $Z, Z_{D R}$, and $K_{D P}$ with Different Drop Shapes. The histograms of occurrence frequency for polarimetric variables, $Z, Z_{\mathrm{DR}}$, and $K_{\mathrm{DP}}$, calculated by DSDs data for 4 years in Busan with different raindrop axis ratio relations, DS1, DS3, and DS6, were shown in Figure 5.

The averages and modes of $Z$ were around $26.2 \mathrm{dBZ}$ and 32 33 dBZ for all raindrop axis assumptions (Figures 5(a) $5(c))$. It means that the reflectivity is not sensitive to the drop axis relation. In case of $Z_{\mathrm{DR}}$, there were two modes of occurrence for all cases. The averages and standard deviation of each relation were $0.63 \mathrm{~dB}$ and $0.91 \mathrm{~dB}$ for $\mathrm{DS} 1,0.61 \mathrm{~dB}$ and $0.8 \mathrm{~dB}$ for DS3, and $0.66 \mathrm{~dB}$ and $0.82 \mathrm{~dB}$ for DS6. The low and 
TABLE 2: The rainfall relations of $R(Z), R\left(Z_{\mathrm{DR}}\right), R\left(K_{\mathrm{DP}}\right), R\left(Z, Z_{\mathrm{DR}}\right)$, and $R\left(K_{\mathrm{DP}}, Z_{\mathrm{DR}}\right)$ with different raindrop shape assumptions.

\begin{tabular}{llllcc}
\hline DS & $R(Z)$ & $R\left(Z_{\mathrm{DR}}\right)$ & $R\left(K_{\mathrm{DP}}\right)$ & $R\left(Z, Z_{\mathrm{DR}}\right)$ & $R\left(K_{\mathrm{DP}}, Z_{\mathrm{DR}}\right)$ \\
\hline DS1 & $R=0.0273 Z^{0.60}$ & $R=0.29 Z_{\mathrm{DR}}{ }^{5.27}$ & $R=44.5 K_{\mathrm{DP}}{ }^{0.942}$ & $R=0.016 Z^{0.889} Z_{\mathrm{DR}}{ }^{-4.94}$ & $R=53.7 K_{\mathrm{DP}}{ }^{0.857} Z_{\mathrm{DR}}{ }^{-1.48}$ \\
DS2 & $R=0.0277 Z^{0.59}$ & $R=0.38 Z_{\mathrm{DR}}{ }^{4.87}$ & $R=53.3 K_{\mathrm{DP}}{ }^{0.913}$ & $R=0.014 Z^{0.852} Z_{\mathrm{DR}}{ }^{-4.08}$ & $R=75.2 K_{\mathrm{DP}}{ }^{0.855} Z_{\mathrm{DR}}{ }^{-1.98}$ \\
DS3 & $R=0.0277 Z^{0.60}$ & $R=0.42 Z_{\mathrm{DR}}{ }^{4.98}$ & $R=61.5 K_{\mathrm{DP}}{ }^{0.908}$ & $R=0.015 Z^{0.818} Z_{\mathrm{DR}}{ }^{-3.72}$ & $R=82.2 K_{\mathrm{DP}}{ }^{0.855} Z_{\mathrm{DR}}{ }^{-1.98}$ \\
DS4 & $R=0.0277 Z^{0.60}$ & $R=0.41 Z_{\mathrm{DR}}{ }^{4.98}$ & $R=59.9 K_{\mathrm{DP}}{ }^{0.896}$ & $R=0.014 Z^{0.844} Z_{\mathrm{DR}}{ }^{-4.06}$ & $R=67.4 K_{\mathrm{DP}}{ }^{0.785} Z_{\mathrm{DR}}{ }^{-2.13}$ \\
DS5 & $R=0.0277 Z^{0.60}$ & $R=0.40 Z_{\mathrm{DR}}{ }^{5.03}$ & $R=56.2 K_{\mathrm{DP}}{ }^{0.897}$ & $R=0.013 Z^{0.861} Z_{\mathrm{DR}}{ }^{-4.3}$ & $R=84.7 K_{\mathrm{DP}}{ }^{0.840} Z_{\mathrm{DR}}{ }^{-2.38}$ \\
DS6 & $R=0.0280 Z^{0.59}$ & $R=0.43 Z_{\mathrm{DR}}{ }^{4.69}$ & $R=56.3 K_{\mathrm{DP}}{ }^{0.857}$ & $R=0.013 Z^{0.857} Z_{\mathrm{DR}}{ }^{-4.0}$ & $R=15.0 K_{\mathrm{DP}}{ }^{0.483} Z_{\mathrm{DR}}{ }^{-0.77}$ \\
\hline
\end{tabular}

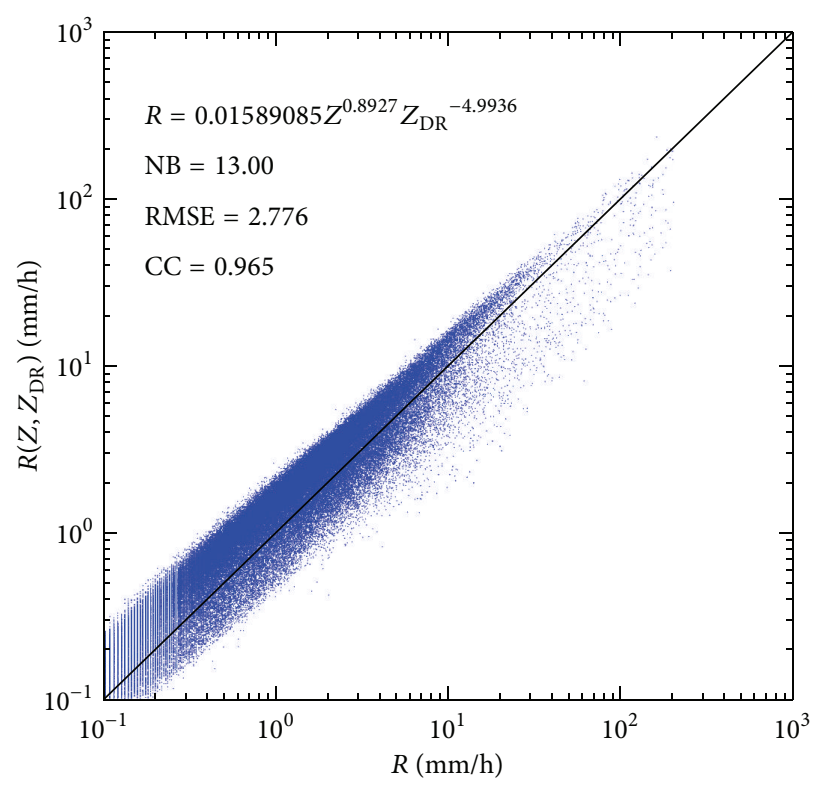

(a)

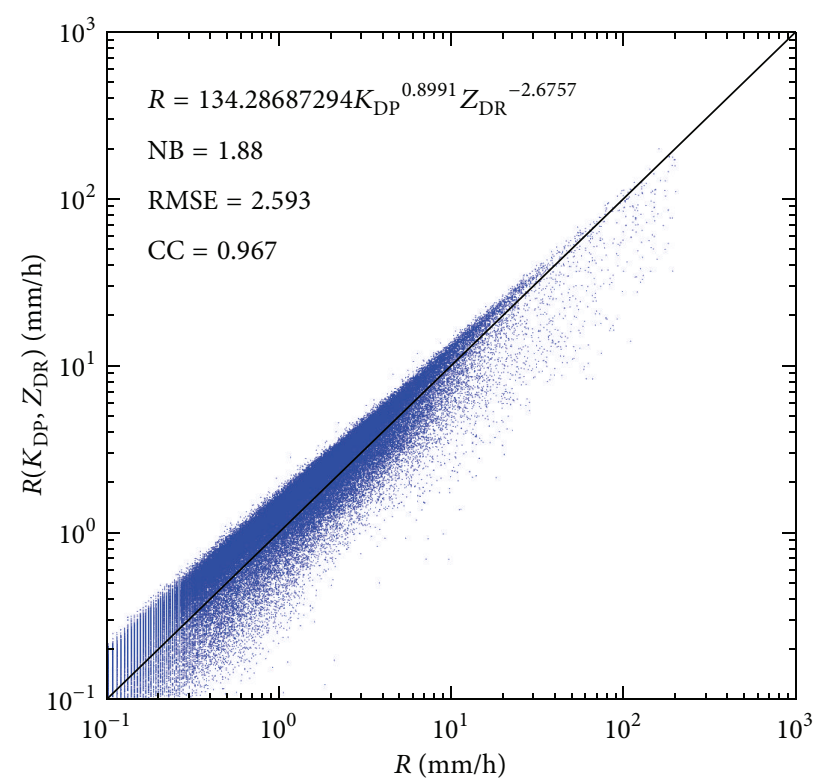

(b)

FIGURE 6: The scatter plots of rainfall obtained by DSDs and (a) $R\left(Z, Z_{\mathrm{DR}}\right)$ and (b) $R\left(K_{\mathrm{DP}}, Z_{\mathrm{DR}}\right)$ using $Z$ for DS3, $Z_{\mathrm{DR}}$ for DS1, and $K_{\mathrm{DP}}$ for DS3.

high modes of $Z_{\mathrm{DR}}$ with DS1, DS3, and DS6 were 0.2 0.3 dB and $1.7 \sim 1.8 \mathrm{~dB}, 0.2 \sim 0.3 \mathrm{~dB}$ and $1.6 \sim 1.7 \mathrm{~dB}$, and $0.0 \sim 0.1 \mathrm{~dB}$ and $1.7 \sim 1.8 \mathrm{~dB}$, respectively. The occurrence frequencies of low mode for each raindrop axis ratio were significantly different from each other (Figures 5(d) 5(f)). The averages and standard deviation of $K_{\mathrm{DP}}$ with different raindrop shapes were 0.11 and $0.04,0.09$ and 0.03 , and 0.1 and 0.03 , respectively. The modes of all drop shapes were the same, but the occurrence frequencies were different (Figures 5(g) 5(i)).

3.1.2. The Statistics of Rainfall Relations with Different Raindrop Axis Ratios. Because the occurrence frequencies of $Z_{\mathrm{DR}}$ and $K_{\mathrm{DP}}$ with different raindrop axis ratios were different from each other, the rainfall relations using those variables should be different with drop shape assumptions. Table 2 shows the rainfall relations obtained by using different raindrop shape assumptions. The coefficients of $R(Z)$ were not significantly different with drop shape assumptions; however those of other relations were different with each drop shape.

Table 3 shows the cross correlations (hereinafter CC) and RMSEs (root mean square errors) of rainfall relations, $R(Z)$, $R\left(Z_{\mathrm{DR}}\right), R\left(K_{\mathrm{DP}}\right), R\left(Z, Z_{\mathrm{DR}}\right)$, and $R\left(K_{\mathrm{DP}}, Z_{\mathrm{DR}}\right)$, obtained by calculations using DSDs data with different raindrop shapes.
The statistics of $R(Z)$ and $R\left(Z_{\mathrm{DR}}\right)$ were not significantly different with raindrop shapes. The CC and RMSE of $R\left(Z_{\mathrm{DR}}\right)$ and $R\left(Z, Z_{\mathrm{DR}}\right)$ were the worst and the best among the other rainfall relations. The statistics of $R\left(K_{\mathrm{DR}}\right), R\left(Z, Z_{\mathrm{DR}}\right)$, and $R\left(K_{\mathrm{DP}}, Z_{\mathrm{DR}}\right)$ were much more variable with different raindrop axis ratios than the ones of $R(Z)$ and $R\left(Z_{\mathrm{DR}}\right)$. The RMSEs of $R\left(K_{\mathrm{DP}}\right), R\left(Z, Z_{\mathrm{DR}}\right)$, and $R\left(K_{\mathrm{DP}}, Z_{\mathrm{DR}}\right)$ with raindrop shapes were distributed from 3.030 to $3.828 \mathrm{~mm}, 2.965$ to $3.523 \mathrm{~mm}$, and 3.151 to $5.412 \mathrm{~mm}$, respectively. The best performance of each relation occurred at DS3 for $R(Z)$, DS1 for $R\left(Z_{\mathrm{DR}}\right)$, DS1 for $R\left(K_{\mathrm{DP}}\right)$, DS1 for $R\left(Z, Z_{\mathrm{DR}}\right)$, and DS3 for $R\left(K_{\mathrm{DP}}, Z_{\mathrm{DR}}\right)$.

In order to calculate more accurate $R\left(Z, Z_{\mathrm{DR}}\right)$ and $R\left(K_{\mathrm{DP}}, Z_{\mathrm{DR}}\right)$, the $Z$ and $Z_{\mathrm{DR}}$ with the best performance were chosen. Figure 6 shows the scatter plots of rainfall obtained by DSDs and $R\left(Z, Z_{\mathrm{DR}}\right)$ and $R\left(K_{\mathrm{DP}}, Z_{\mathrm{DR}}\right)$ using the best statistics among raindrop axis ratio. $Z, Z_{\mathrm{DR}}$, and $K_{\mathrm{DP}}$ were chosen from DS3, DS1, and DS1, respectively. Comparing with $R\left(Z, Z_{\mathrm{DR}}\right)$ and $R\left(K_{\mathrm{DP}}, Z_{\mathrm{DR}}\right)$ of single raindrop axis ratio relations having the best performance, new combined relations had better RMSE and CC. The RMSEs of new relations, $R\left(Z, Z_{\mathrm{DR}}\right)$ and $R\left(K_{\mathrm{DP}}, Z_{\mathrm{DR}}\right)$, had better score as much as around $0.2 \mathrm{~mm}$ and $0.6 \mathrm{~mm}$, respectively. Even though 
TABLE 3: The correlation coefficients and RMSEs $(\mathrm{mm})$ of rainfall obtained by rainfall relations and DSDs. CC means cross correlation.

\begin{tabular}{lcccccccccc}
\hline \multirow{2}{*}{ DS } & \multicolumn{2}{c}{$R(Z)$} & \multicolumn{2}{c}{$R\left(Z_{\mathrm{DR}}\right)$} & \multicolumn{2}{c}{$R\left(K_{\mathrm{DP}}\right)$} & \multicolumn{2}{c}{$R\left(Z, Z_{\mathrm{DR}}\right)$} & \multicolumn{2}{c}{$R\left(K_{\mathrm{DP}}, Z_{\mathrm{DR}}\right)$} \\
& $\mathrm{CC}$ & RMSE & CC & RMSE & CC & RMSE & CC & RMSE & CC & RMSE \\
\hline DS1 & 0.913 & 4.705 & 0.572 & 6.241 & 0.875 & 3.030 & 0.964 & 2.965 & 0.951 & 3.313 \\
DS2 & 0.913 & 4.709 & 0.569 & 6.248 & 0.861 & 3.198 & 0.956 & 3.272 & 0.956 \\
DS3 & 0.914 & 4.704 & 0.562 & 6.261 & 0.861 & 3.178 & 0.949 & 3.523 & 0.960 & 3.222 \\
DS4 & 0.913 & 4.706 & 0.569 & 6.249 & 0.828 & 3.549 & 0.954 & 3.334 & 0.931 & 3.882 \\
DS5 & 0.913 & 4.706 & 0.572 & 6.243 & 0.849 & 3.326 & 0.957 & 3.210 & 0.950 & 3.348 \\
DS6 & 0.913 & 4.713 & 0.572 & 6.244 & 0.795 & 3.828 & 0.956 & 3.239 & 0.814 & 5.412 \\
\hline
\end{tabular}

TABLE 4: The rainfall relations, NE, RMSE, and CC of each raindrop axis ratio relation.

\begin{tabular}{|c|c|c|c|c|}
\hline $\begin{array}{l}\text { Drop } \\
\text { Shape }\end{array}$ & Relation & NE & RMSE & $\mathrm{CC}$ \\
\hline \multirow{3}{*}{ DS1 } & $R\left(K_{\mathrm{DP}}\right)=44.5 K_{\mathrm{DP}}^{0.942}$ & 0.52 & 4.996 & 0.82 \\
\hline & $R\left(Z, Z_{\mathrm{DR}}\right)=0.0157 Z^{0.889} Z_{\mathrm{DR}}^{-4.94}$ & 0.31 & 4.802 & 0.97 \\
\hline & $R\left(K_{\mathrm{DP}}, Z_{\mathrm{DR}}\right)=53.7 K_{\mathrm{DP}}^{0.857} Z_{\mathrm{DR}}^{-1.48}$ & 0.56 & 5.262 & 0.88 \\
\hline \multirow{3}{*}{ DS2 } & $R\left(K_{\mathrm{DP}}\right)=53.0 K_{\mathrm{DP}}^{0.913}$ & 0.52 & 4.645 & 0.78 \\
\hline & $R\left(Z, Z_{\mathrm{DR}}\right)=0.0141 Z^{0.853} Z_{\mathrm{DR}}^{-4.08}$ & 0.36 & 3.793 & 0.73 \\
\hline & $R\left(K_{\mathrm{DP}}, Z_{\mathrm{DR}}\right)=75.2 K_{\mathrm{DP}}^{0.855} Z_{\mathrm{DR}}^{-1.98}$ & 0.60 & 5.146 & 0.73 \\
\hline \multirow{3}{*}{ DS3 } & $R\left(K_{\mathrm{DP}}\right)=61.5 K_{\mathrm{DP}}^{0.908}$ & 0.55 & 4.698 & 0.78 \\
\hline & $R\left(Z, Z_{\mathrm{DR}}\right)=0.0148 Z^{0.818} Z_{\mathrm{DR}}^{-3.72}$ & 0.43 & 4.479 & 0.89 \\
\hline & $R\left(K_{\mathrm{DP}}, Z_{\mathrm{DR}}\right)=82.2 K_{\mathrm{DP}}{ }^{0.855} Z_{\mathrm{DR}}{ }^{-1.98}$ & 0.63 & 5.247 & 0.73 \\
\hline \multirow{3}{*}{ DS4 } & $R\left(K_{\mathrm{DP}}\right)=59.9 K_{\mathrm{DP}}^{0.896}$ & 0.54 & 4.673 & 0.78 \\
\hline & $R\left(Z, Z_{\mathrm{DR}}\right)=0.0136 Z^{0.840} Z_{\mathrm{DR}}^{-4.06}$ & 0.40 & 4.134 & 0.89 \\
\hline & $R\left(K_{\mathrm{DP}}, Z_{\mathrm{DR}}\right)=67.4 K_{\mathrm{DP}}{ }^{0.785} Z_{\mathrm{DR}}{ }^{-2.13}$ & 0.60 & 5.249 & 0.73 \\
\hline \multirow{3}{*}{ DS5 } & $R\left(K_{\mathrm{DP}}\right)=56.2 K_{\mathrm{DP}}^{0.897}$ & 0.53 & 4.625 & 0.78 \\
\hline & $R\left(Z, Z_{\mathrm{DR}}\right)=0.0133 Z^{0.861} Z_{\mathrm{DR}}^{-4.31}$ & 0.37 & 3.900 & 0.88 \\
\hline & $R\left(K_{\mathrm{DP}}, Z_{\mathrm{DR}}\right)=84.7 K_{\mathrm{DP}}^{0.840} Z_{\mathrm{DR}}{ }^{-2.38}$ & 0.65 & 5.390 & 0.71 \\
\hline \multirow{3}{*}{ DS6 } & $R\left(K_{\mathrm{DP}}\right)=56.3 K_{\mathrm{DP}}^{0.857}$ & 0.54 & 4.647 & 0.78 \\
\hline & $R\left(Z, Z_{\mathrm{DR}}\right)=0.0125 Z^{0.857} Z_{\mathrm{DR}}^{-3.99}$ & 0.38 & 3.967 & 0.89 \\
\hline & $R\left(K_{\mathrm{DP}}, Z_{\mathrm{DR}}\right)=15.0 K_{\mathrm{DP}}^{0.483} Z_{\mathrm{DR}}^{-0.77}$ & 0.65 & 7.141 & 0.76 \\
\hline
\end{tabular}

the CC and RMSE of $R(Z)$ and $R\left(Z_{\mathrm{DR}}\right)$ with different drop shapes were not significant, the combined relations had better performance.

\subsection{Validations of Rainfall Relations with Different Raindrop} Axis Ratio Relations. To investigate the performance of rainfall relations, NE (normalized error), RMSE, and CC were calculated using rainfall from each relation with six raindrop shapes and that of gage rainfall.

Table 4 summarizes the relations and the statistics such as NE, RMSE, and CC. The NEs and RMSEs of $R\left(K_{\mathrm{DR}}\right)$ calculated by each raindrop axis were distributed from 0.52 to 0.55 and from 4.625 to 4.996 , respectively. The $R\left(K_{\mathrm{DR}}\right)$ with assumption of DS5 was the best score of RMSE in other raindrop shapes. In case of $R\left(Z, Z_{\mathrm{DR}}\right)$, the distribution of NEs and RMSEs was from 0.31 to 0.43 and from 3.793 to 4.602 , respectively. The best RMSE score of $R\left(Z, Z_{\mathrm{DR}}\right)$ was from DS2. The NEs and RMSEs of $R\left(K_{\mathrm{DP}}, Z_{\mathrm{DR}}\right)$ occurred from 0.55 to 0.65 and from 5.146 to 7.141, respectively. The performance of
$R\left(K_{\mathrm{DP}}, Z_{\mathrm{DR}}\right)$ was the worst score and $R\left(Z, Z_{\mathrm{DR}}\right)$ had the best score in all raindrop axis ratio relations. The performances of validation were different from that of rainfall relation calculation. It would be caused by the variations of DSDs in this study.

To compare the performance between new combined $R\left(K_{\mathrm{DP}}, Z_{\mathrm{DR}}\right)$ and $R\left(Z, Z_{\mathrm{DR}}\right)$, the statistics were also calculated. Figure 7 shows the scatter plots rainfall from rainfall relation and gage rainfall with some statistics. The NE and RMSE of two relations from single raindrop shape assumption showed better results. However, it seems that the $R\left(Z, Z_{\mathrm{DR}}\right)$ with two-raindrop axis ratio was more close to the gage rainfall in the range of weaker than $20 \mathrm{~mm} / \mathrm{h}$ and the $R\left(K_{\mathrm{DP}}, Z_{\mathrm{DR}}\right)$ with two drop shapes was more accurate in the rainfall of higher than $20 \mathrm{~mm} / \mathrm{h}$.

\subsection{Rainfall Estimation Using Specific Attenuation}

3.3.1. Calculation of Specific Attenuation. The $A_{H}$ can be calculated from the radial profile of the attenuated reflectivity $Z_{a}$ and the two-way PIA (Path Integrated Attenuation) along the propagation path $\left(r_{1}, r_{2}\right)$ proposed by Meneghini and Nakamura [34]:

$$
A(r)=\frac{a(r)\left[Z_{a}\right]^{b} C(b, \mathrm{PIA})}{I_{a}\left(r_{1}, r_{2}\right)+C(b, \mathrm{PIA}) I_{a}\left(r, r_{2}\right)},
$$

where

$$
\begin{gathered}
I_{a}\left(r_{1}, r_{2}\right)=0.46 b \int_{r_{1}}^{r_{2}} a(s)\left[Z_{a}(s)\right]^{b} d s, \\
I_{a}\left(r, r_{2}\right)=0.46 b \int_{r}^{r_{2}} a(s)\left[Z_{a}(s)\right]^{b} d s .
\end{gathered}
$$

If $a$ is not dependent on range, then (8) becomes

$$
A(r)=\frac{\left[Z_{a}\right]^{b} C(b, \mathrm{PIA})}{I_{a}\left(r_{1}, r_{2}\right)+C(b, \mathrm{PIA}) I_{a}\left(r, r_{2}\right)},
$$

where

$$
\begin{aligned}
I_{a}\left(r_{1}, r_{2}\right) & =0.46 b \int_{r_{1}}^{r_{2}}\left[Z_{a}(s)\right]^{b} d s, \\
I_{a}\left(r, r_{2}\right) & =0.46 b \int_{r}^{r_{2}}\left[Z_{a}(s)\right]^{b} d s, \\
C(b, \mathrm{PIA}) & =\exp (0.23 b \mathrm{PIA})-1 .
\end{aligned}
$$




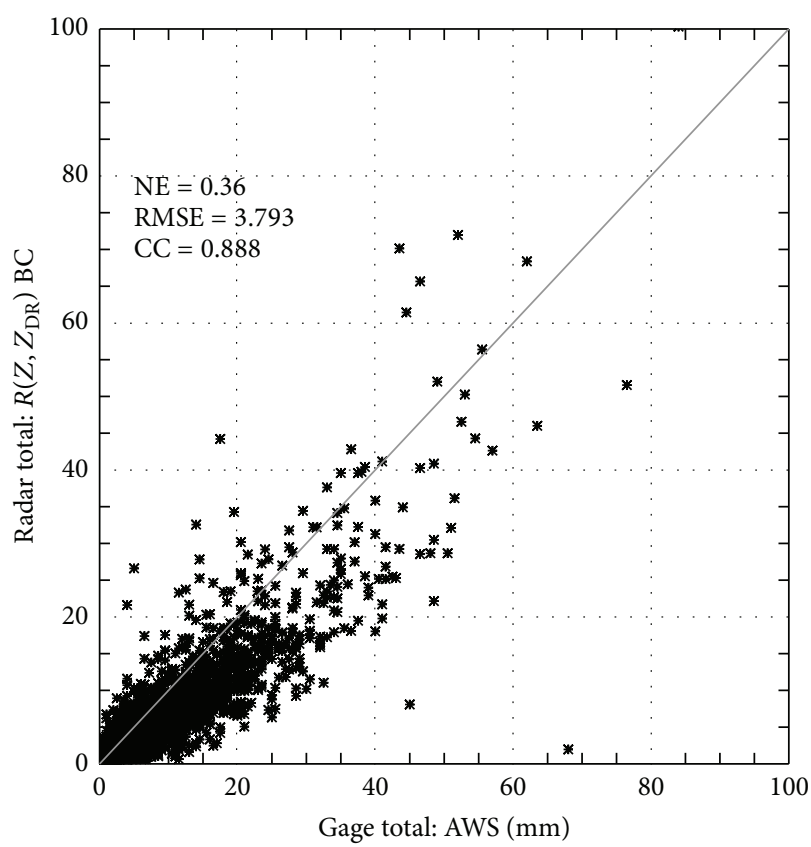

(a)

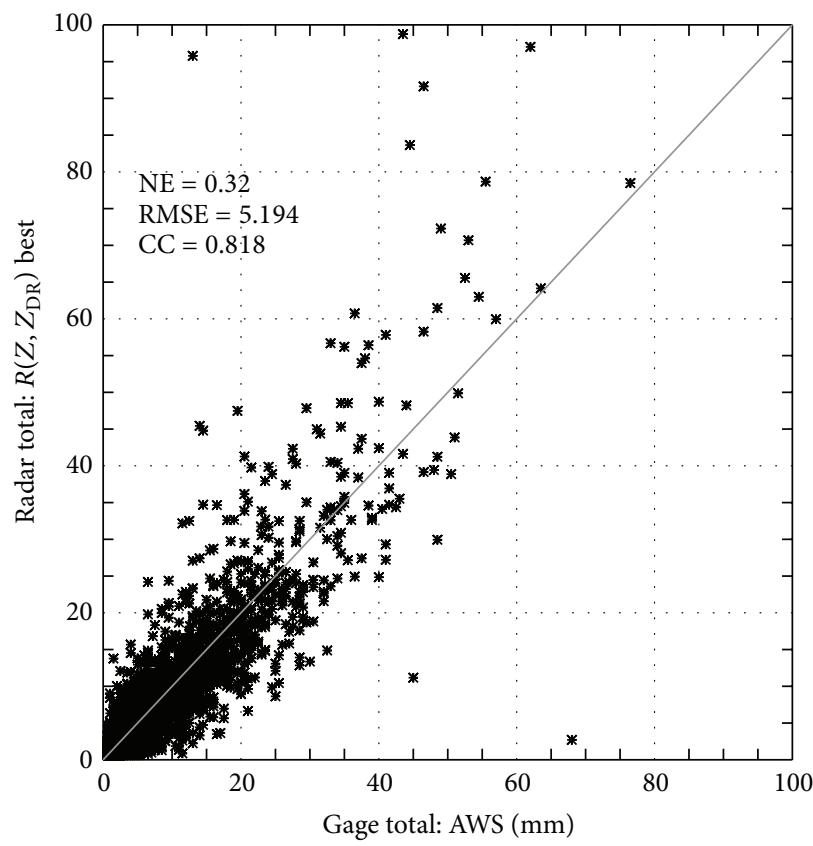

(c)

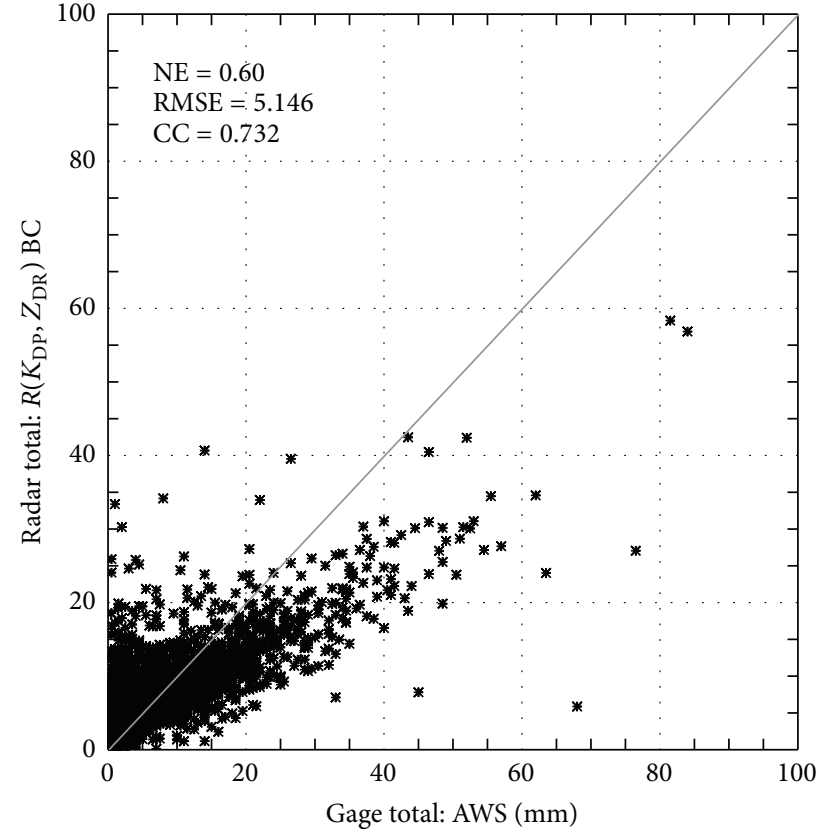

(b)

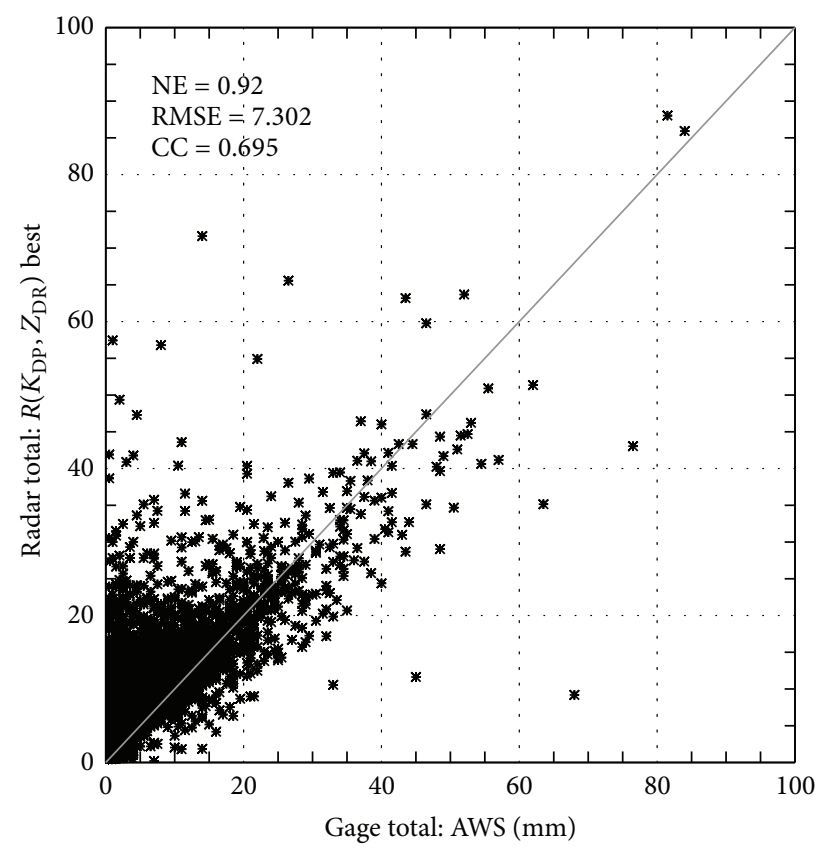

(d)

FIGURE 7: The scatter plot of rainfall from gage and (a) $R\left(Z, Z_{\mathrm{DR}}\right)$, (b) $R\left(K_{\mathrm{DP}}, Z_{\mathrm{DR}}\right)$ with single raindrop axis ratio relation, (c) $R\left(Z, Z_{\mathrm{DR}}\right)$, and (d) $R\left(K_{\mathrm{DP}}, Z_{\mathrm{DR}}\right)$ with two-raindrop axis ratio relation. by

Bringi et al. [35] recommended estimating PIA using $\Phi_{\mathrm{DP}}$

$$
\operatorname{PIA}\left(r_{1}, r_{2}\right)=\alpha\left[\Phi_{\mathrm{DP}}\left(r_{2}\right)-\Phi_{\mathrm{DP}}\left(r_{1}\right)\right]=\alpha \Delta \Phi_{\mathrm{DP}}
$$

and Testud et al. [36] used (10) and (12) to obtain radial profiles of $A_{H}$ at C-band. In this study, $A_{H}$ was calculated by the method proposed by Ryzhkov et al. [23]. The constant $b$ was set by 0.6 and $\alpha$ was by 0.027 calculated by the ratio of $A_{H}$ to $K_{\mathrm{DP}}$ obtained from DSDs.

Figure 8 shows the scatter plot of rainfall from $R(Z)$, $R\left(K_{\mathrm{DP}}\right)$, and $R\left(A_{H}\right)$ and rainfall from DSDs and an PPIs (Plan Position Indicators) at 0.5 degree elevation angle of gage rainfall and rainfall from $R\left(K_{\mathrm{DP}}\right)$ and $R\left(A_{H}\right)$ at $0251 \mathrm{KST}$ on the 8th of August in 2011.

The $R\left(A_{H}\right)$ relation had much better fit to the rainfall of DSDs than that of $R\left(K_{\mathrm{DP}}\right)$ and $R(Z)$ relation. Comparing with 


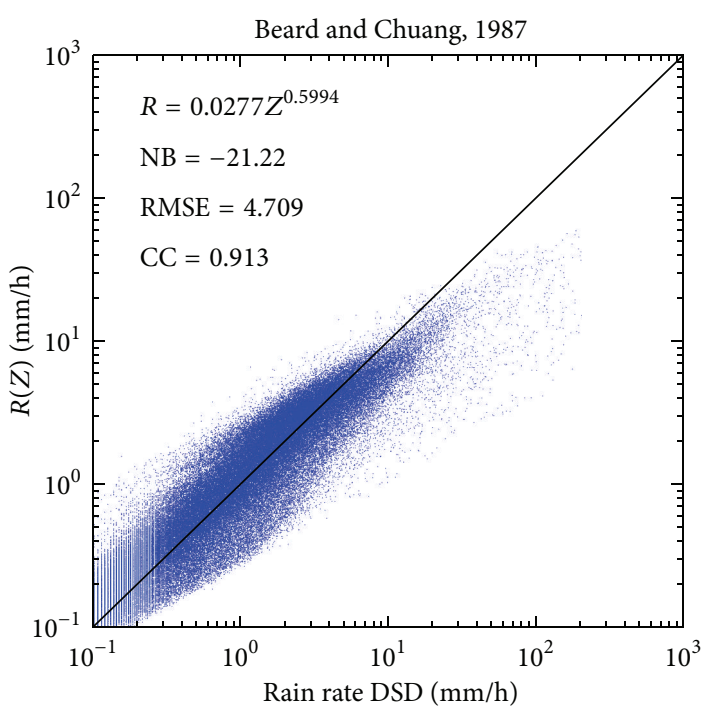

(a)

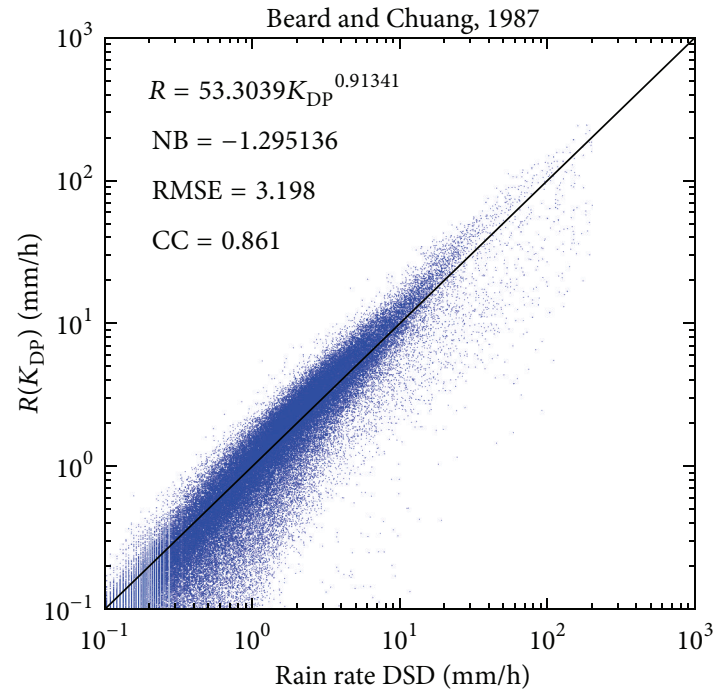

(b)

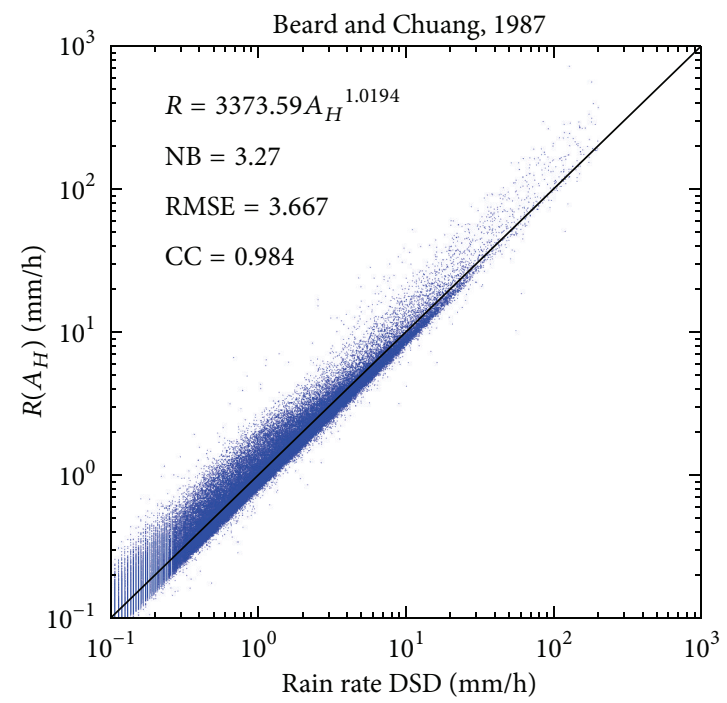

(c)

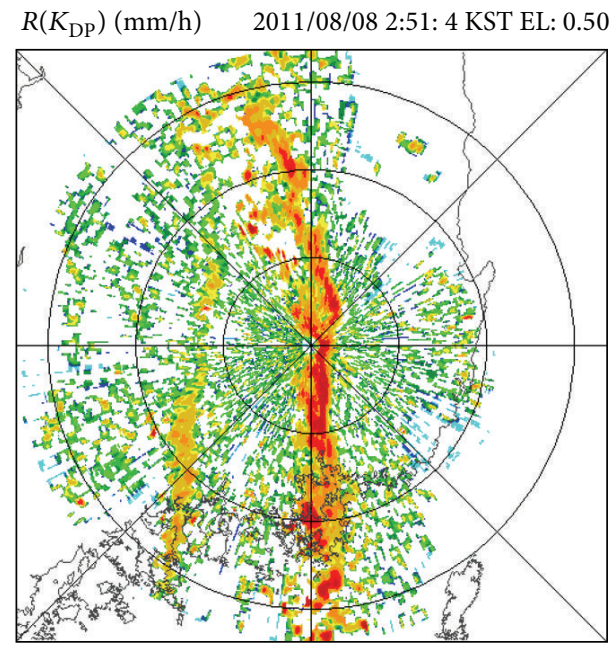

BSL range: $101 \mathrm{~km}$ Bin size: $0.125 \mathrm{~km}$ Bins: 813

(d)

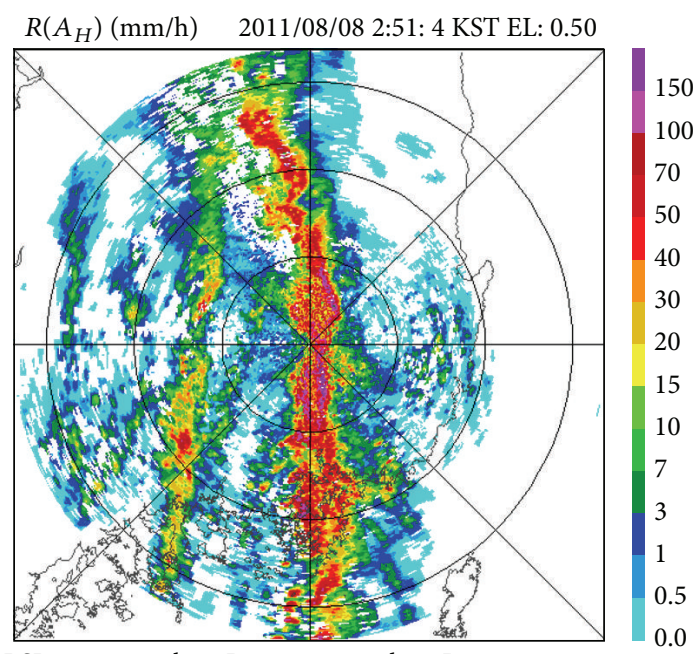

BSL range: $101 \mathrm{~km}$ Bin size: $0.125 \mathrm{~km}$ Bins: 813

(e)

FiguRE 8: The scatter plot of (a) $R(Z)$, (b) $R\left(K_{\mathrm{DP}}\right)$, and (c) $R\left(A_{H}\right)$ with statistics and the rainfall distribution of $R\left(K_{\mathrm{DP}}\right)$ and $R\left(A_{H}\right)$ at 0251 KST on the 8th of August in 2001. 
TABLE 5: The rainfall relations of $R\left(Z, K_{\mathrm{DP}}, A_{H}\right)$ and $R\left(Z, Z_{\mathrm{DR}}, K_{\mathrm{DP}}, A_{H}\right)$ with different raindrop shape assumptions.

\begin{tabular}{lcc}
\hline DS & $R\left(Z, K_{\mathrm{DP}}, A_{H}\right)$ & $R\left(Z, Z_{\mathrm{DR}}, K_{\mathrm{DP}}, A_{H}\right)$ \\
\hline DS1 & $R=1527 Z^{-0.04} K_{\mathrm{DP}}{ }^{0.327} A_{H}{ }^{0.713}$ & $R=310 Z^{0.12} Z_{\mathrm{DR}}{ }^{-0.83} K_{\mathrm{DP}}{ }^{0.304} A_{H}{ }^{0.677}$ \\
DS2 & $R=12012 Z^{-0.24} K_{\mathrm{DP}}{ }^{0.551} A_{H}{ }^{0.685}$ & $R=4947 Z^{-0.15} Z_{\mathrm{DR}}{ }^{-0.26} K_{\mathrm{DP}}{ }^{0.468} A_{H}{ }^{0.681}$ \\
DS3 & $R=17211 Z^{-0.27} K_{\mathrm{DP}}{ }^{0.619} A_{H}{ }^{0.650}$ & $R=4502 Z^{0.14} Z_{\mathrm{DR}}{ }^{-0.39} K_{\mathrm{DP}}{ }^{0.486} A_{H}{ }^{0.653}$ \\
DS4 & $R=10798 Z^{-0.19} K_{\mathrm{DP}}{ }^{0.403} A_{H}{ }^{0.778}$ & $R=193 Z^{0.18} Z_{\mathrm{DR}}{ }^{-1.11} K_{\mathrm{DP}}{ }^{0.114} A_{H}{ }^{0.702}$ \\
DS5 & $R=20275 Z^{-0.27} K_{\mathrm{DP}}{ }^{0.543} A_{H}{ }^{0.720}$ & $R=24 Z^{0.37} Z_{\mathrm{DR}}{ }^{-1.47} K_{\mathrm{DP}}{ }^{-0.025} A_{H}{ }^{0.656}$ \\
DS6 & $R=397 Z^{-0.11} K_{\mathrm{DP}}{ }^{0.044} A_{H}^{0.808}$ & $R=571 Z^{0.07} Z_{\mathrm{DR}}{ }^{-0.92} K_{\mathrm{DP}}{ }^{0.238} A_{H}{ }^{0.687}$ \\
\hline
\end{tabular}

the distribution of rainfall obtained by $R\left(K_{\mathrm{DP}}\right)$ and $R\left(A_{H}\right)$, $R\left(A_{H}\right)$ has better spatial resolution and more homogeneous pattern than those of $R\left(K_{\mathrm{DP}}\right)$.

3.3.2. Validations of $R\left(A_{H}\right), R\left(Z, K_{D P}, A_{H}\right)$, and $R\left(Z, Z_{D R}\right.$, $\left.K_{D P}, A_{H}\right)$ Relations. As mentioned in the previous section, $R\left(A_{H}\right)$ has the potential to be the best choice for estimating rainfall using polarimetric variables. To verify the accuracy, $R\left(A_{H}\right), R\left(Z, K_{\mathrm{DP}}, A_{H}\right)$, and $R\left(Z, Z_{\mathrm{DR}}, K_{\mathrm{DP}}, A_{H}\right)$ relations were obtained and the accuracy of $R\left(A_{H}\right), R\left(Z, K_{\mathrm{DP}}, A_{H}\right)$, and $R\left(Z, Z_{\mathrm{DR}}, K_{\mathrm{DP}}, A_{H}\right)$, which had the best performance in the relations calculated by the six raindrop axis ratio relations, were examined by comparing with $R\left(K_{\mathrm{DP}}\right)$.

Figure 9 shows the scatter plot of rainfall from gage rainfall and $R\left(K_{\mathrm{DP}}\right), R\left(A_{H}\right), R\left(Z, K_{\mathrm{DP}}, A_{H}\right)$, and $R\left(Z, Z_{\mathrm{DR}}\right.$, $\left.K_{\mathrm{DP}}, A_{H}\right)$ for 84 hours. The accuracy of $R\left(Z, Z_{\mathrm{DR}}, K_{\mathrm{DP}}, A_{H}\right)$ was the best and $R\left(Z, K_{\mathrm{DP}}, A_{H}\right)$ was the second in 4 relations. $R\left(A_{H}\right)$ was not better than $R\left(K_{\mathrm{DP}}\right)$ in whole range of rainfall. However, in the range of higher rainfall, it seems that $R\left(A_{H}\right)$ was closer to the gage rainfall. The error of $R\left(A_{H}\right)$ would be caused by the missing radial profile of $\Phi_{\mathrm{DP}}$ along the ray. The missing has occurred, if the difference of $\Phi_{\mathrm{DP}}$ between the starting and end gate is negative. According to the results, $R\left(Z, K_{\mathrm{DP}}, A_{H}\right)$ and $R\left(Z, Z_{\mathrm{DR}}, K_{\mathrm{DP}}, A_{H}\right)$ would compensate for this region.

3.4. Optimum Rainfall Algorithm. To find out the optimum rainfall algorithm for Korean S-band polarimetric radar, the gage rainfall amount was categorized by three steps, 0 to $5 \mathrm{~mm} / \mathrm{h}$ assigned as light rain, 5 to $30 \mathrm{~mm} / \mathrm{h}$ as medium rain, and higher than $30 \mathrm{~mm} / \mathrm{h}$ as high rain. In previous section, the relations have different accuracy not only for the raindrop axis ratio relation but also for rainfall amount. The sample numbers for each category were 3,322 samples, 1,980 samples, and 92 samples, respectively.

Figure 10 shows the RMSEs of $R\left(K_{\mathrm{DP}}\right), R\left(Z, Z_{\mathrm{DR}}\right)$, $R\left(K_{\mathrm{DP}}, Z_{\mathrm{DR}}\right), R\left(Z, K_{\mathrm{DP}}, A_{H}\right)$, and $R\left(Z, Z_{\mathrm{DR}}, K_{\mathrm{DP}}, A_{H}\right)$ with different rainfall categories defined in three steps. All relations have different RMSEs with respect to the raindrop axis ratio relations. $R\left(K_{\mathrm{DP}}\right)$ with $\mathrm{DS} 3, R\left(Z, Z_{\mathrm{DR}}\right)$ with $\mathrm{DS} 2$, and $R\left(K_{\mathrm{DP}}, Z_{\mathrm{DR}}\right)$ with DS3 have the best score at the high rainfall regime, at the low rainfall regime, and at the medium rainfall regime, respectively. Even though $R\left(Z, Z_{\mathrm{DR}}\right)$ has the best performance among other relations in total rainfall events, using different rainfall relations with different rainfall regime would be an optimum rainfall algorithm for Korean S-band polarimetric radar. A possible optimum polarimetric rainfall algorithm can be expressed by

$$
\begin{gathered}
R=0.014 Z^{0.852} Z_{\mathrm{DR}}^{-4.08} \quad 0<\text { Rainfall }<5 \mathrm{~mm} \mathrm{~h}^{-1} \\
R=82.2 K_{\mathrm{DP}}^{0.855} Z_{\mathrm{DR}}^{-1.98} \\
5<\text { Rainfall }<30 \mathrm{~mm} \mathrm{~h}^{-1} \\
R=61.5 K_{\mathrm{DP}}^{0.908} \quad 30 \mathrm{~mm} \mathrm{~h}^{-1}<\text { Rainfall. }
\end{gathered}
$$

Table 5 shows the rainfall relations of $R\left(Z, K_{\mathrm{DP}}, A_{H}\right)$ and $R\left(Z, Z_{\mathrm{DR}}, K_{\mathrm{DP}}, A_{H}\right)$ with different raindrop shape assumptions. The coefficients of each relation with respect to the drop shapes were much different comparing with relations obtained by combining two polarimetric variables.

In case of rainfall relations combined with $A_{H}, R\left(Z, Z_{\mathrm{DR}}\right.$, $\left.K_{\mathrm{DP}}, A_{H}\right)$ has better score than $R\left(Z, K_{\mathrm{DP}}, A_{H}\right)$. Both $R\left(Z, K_{\mathrm{DP}}, A_{H}\right)$ and $R\left(Z, Z_{\mathrm{DR}}, K_{\mathrm{DP}}, A_{H}\right)$ with DS3 showed better result than other raindrop shape assumptions. $R\left(Z, Z_{\mathrm{DR}}, K_{\mathrm{DP}}, A_{H}\right)$ at the low, medium, and high rainfall regimes has similar RMSE to $R\left(Z, Z_{\mathrm{DR}}\right), R\left(K_{\mathrm{DP}}, Z_{\mathrm{DR}}\right)$, and $R\left(K_{\mathrm{DP}}\right)$, respectively.

Equations (14) would be an optimum rainfall algorithm, but there is still a problem to solve how the rainfall categories are defined using radar and gage. Gage does not have good spatial resolution to cover radar resolution like $125 \mathrm{~m}$ or $1 \mathrm{~km}$ and each rainfall relation has its own error at certain rainfall regime. Therefore, $R\left(Z, Z_{\mathrm{DR}}, K_{\mathrm{DP}}, A_{H}\right)$ and $R\left(Z, K_{\mathrm{DP}}, A_{H}\right)$ with DS3 can be used regardless rainfall intensity. And in case $Z_{\mathrm{DR}}$ bias calibration is not available or does not have enough quality for quantitative use, $R\left(Z, K_{\mathrm{DP}}, A_{H}\right)$ with DS3 can be used as a representative rainfall estimation.

\section{Summary and Conclusions}

Polarimetric radars will be main tools to monitor and forecast severe weather and flash flooding within several years in Korea. To get an optimum rainfall algorithm using polarimetric variables observed from Bislsan radar which is the first polarimetric radar in Korea, rainfall cases for 84 hours caused by different conditions, which are Changma front and typhoon, Changma front only, and typhoon only, that occurred in 2011 were analyzed. And rainfall relations were obtained by using long period DSDs with six different raindrop axis ratio relations.

In the analysis of $Z, Z_{\mathrm{DR}}$, and $K_{\mathrm{DP}}$ occurrence frequency, there were two modes of $Z_{\mathrm{DR}}$ occurrence frequency and 


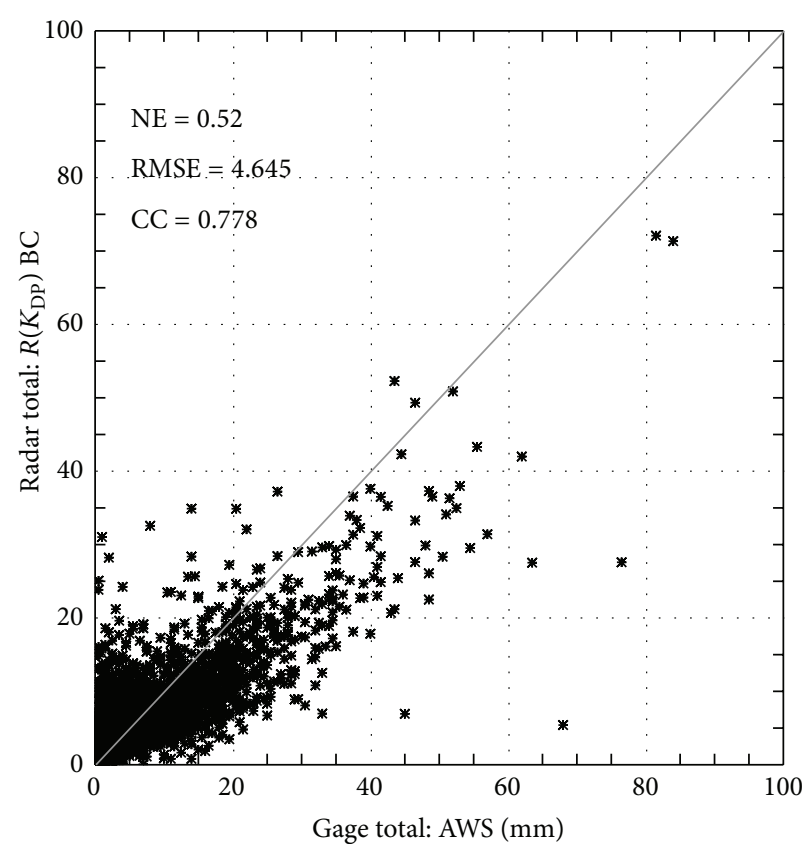

(a)

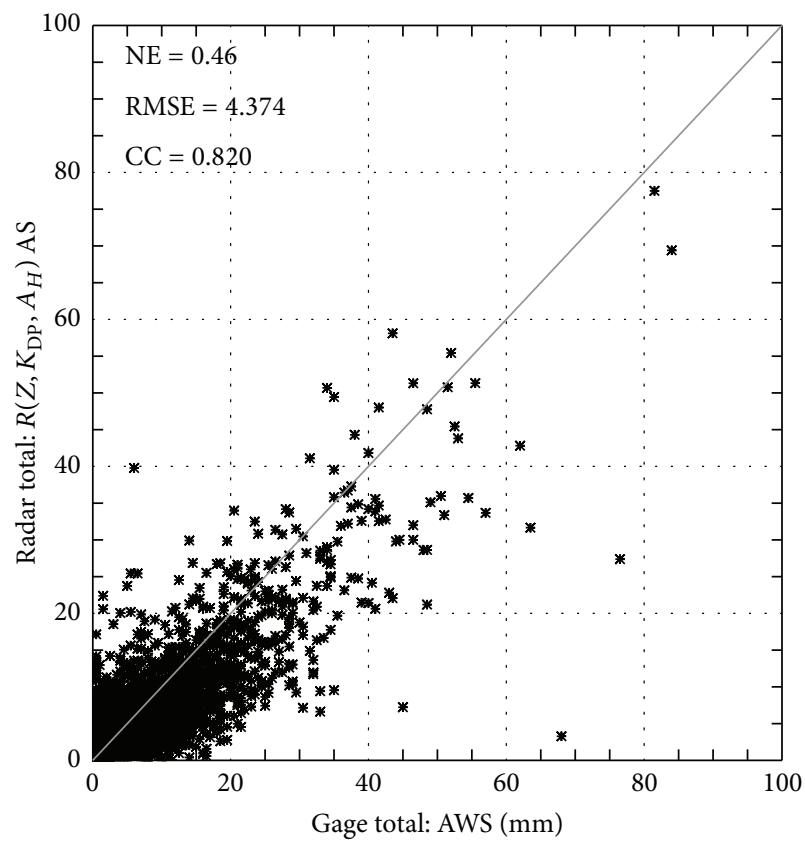

(c)

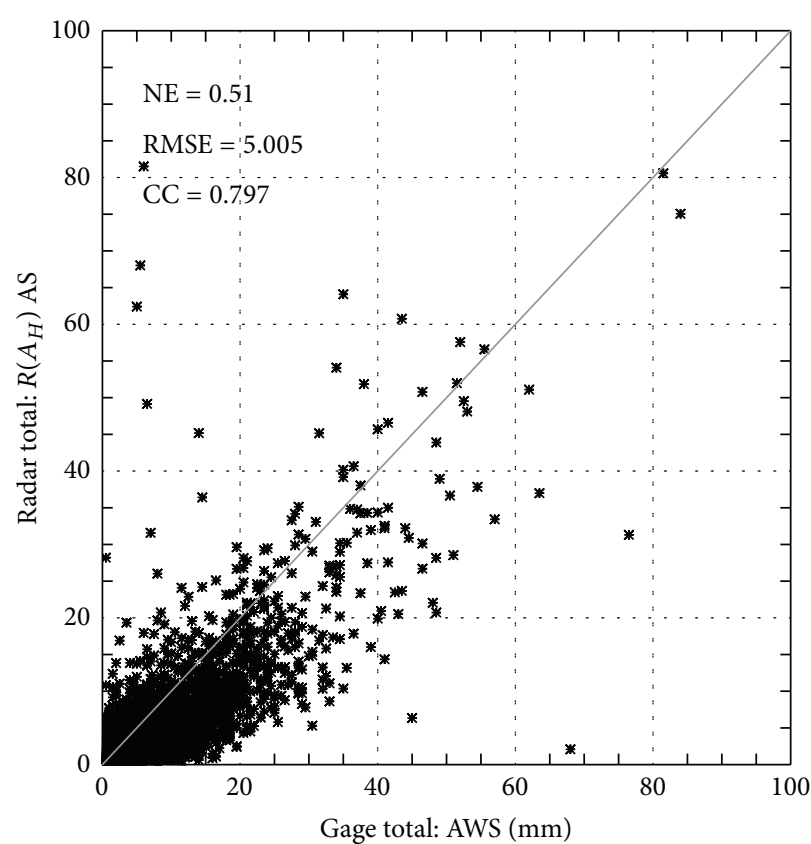

(b)

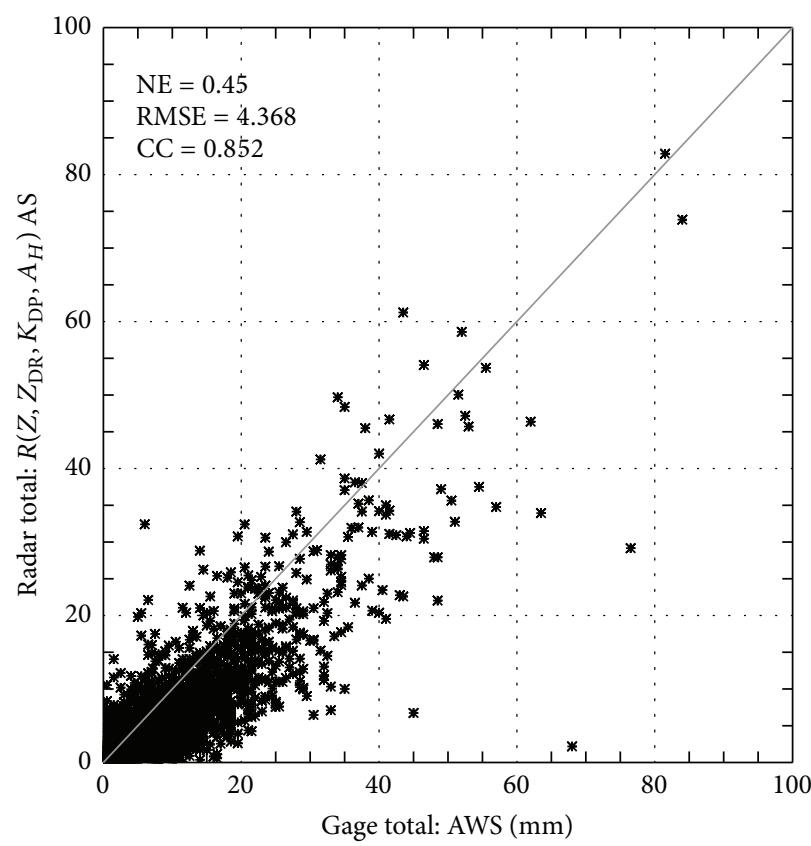

(d)

FIGURE 9: The scatter plot of gage rainfall and $R\left(K_{\mathrm{DP}}\right), R\left(A_{H}\right), R\left(Z, K_{\mathrm{DP}}, A_{H}\right)$, and $R\left(Z, Z_{\mathrm{DP}}, K_{\mathrm{DP}}, A_{H}\right)$ rainfall for 84 hours.

the variations of $K_{\mathrm{DP}}$ and $Z_{\mathrm{DR}}$ histograms were higher than that of $Z$ with raindrop ratio relations. According to these variations, the combined relations of $R\left(Z, Z_{\mathrm{DR}}\right)$ and $R\left(K_{\mathrm{DP}}, Z_{\mathrm{DR}}\right)$ using $Z$ with DS3, $Z_{\mathrm{DR}}$ with $\mathrm{DS} 1$, and $K_{\mathrm{DP}}$ with DS1 were closer to the rainfall of DSDs.

To examine the performance of each rainfall relation, NE, RMSE, CC were calculated using rainfall recorded at 121 gages within radar coverage for 84 hours. The statistics of each rainfall relation were different with raindrop shape assumptions and rainfall intensity. $R\left(K_{\mathrm{DP}}, Z_{\mathrm{DR}}\right)$ had the worst performance and $R\left(Z, Z_{\mathrm{DR}}\right)$ had the best score in all raindrop shapes. $A_{H}$ was calculated by observed $\Phi_{\mathrm{DP}}$ and $Z$ using the method by Ryzhkov et al. [23] and the rainfall relations using $A_{H}$ were also calculated and analyzed.

The performance of rainfall relations were compared with three different rainfall categories to find out an optimum rainfall relation for the $S$-band polarimetric in Korea. $R\left(Z, Z_{\mathrm{DR}}\right)$, $R\left(K_{\mathrm{DP}}, Z_{\mathrm{DR}}\right)$, and $R\left(K_{\mathrm{DP}}\right)$ had the best RMSE at the light 


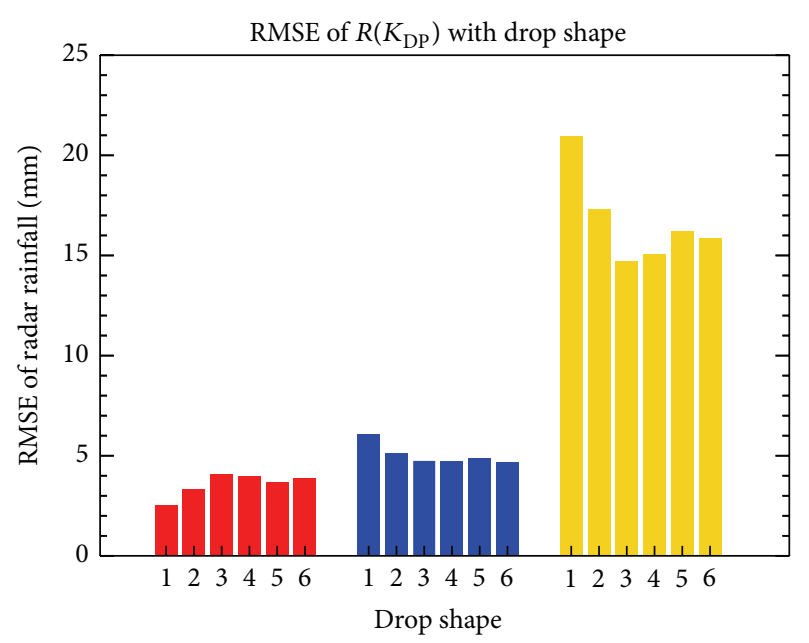

(a)

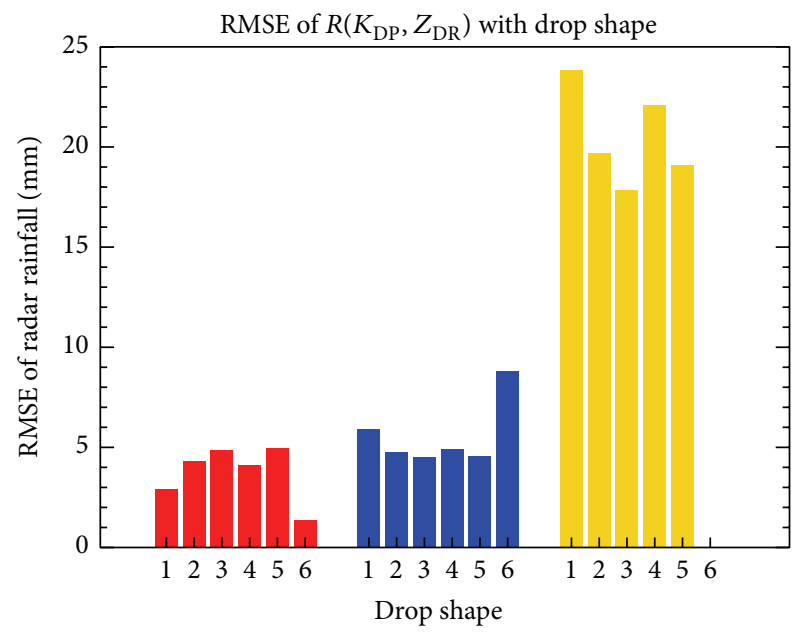

(c)

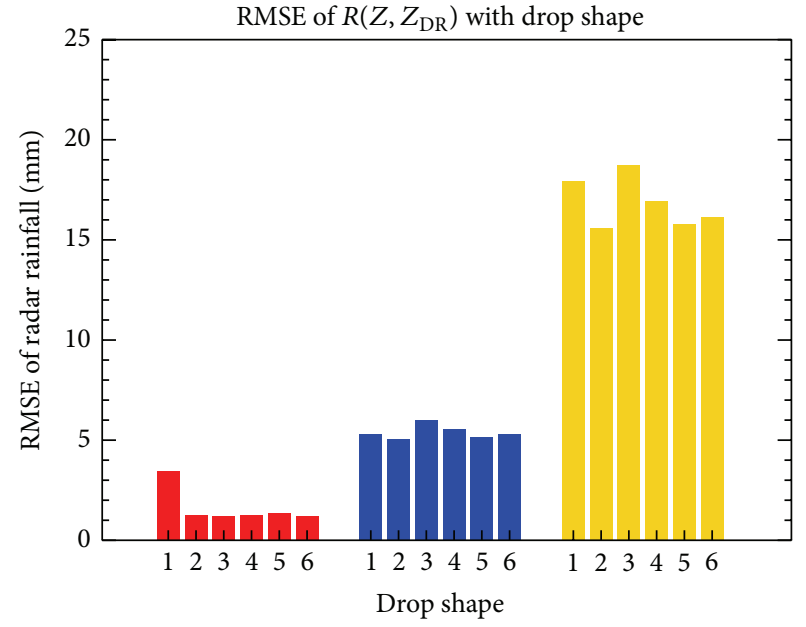

(b)

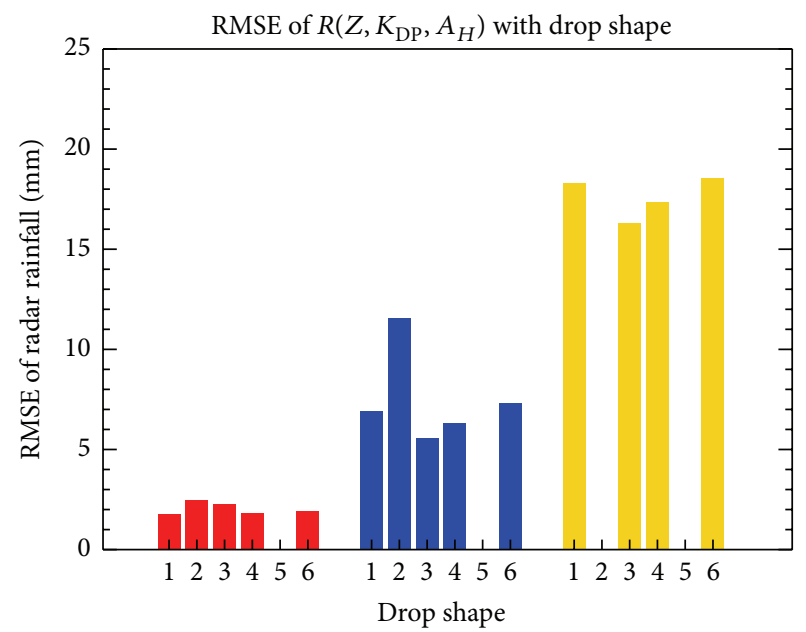

(d)

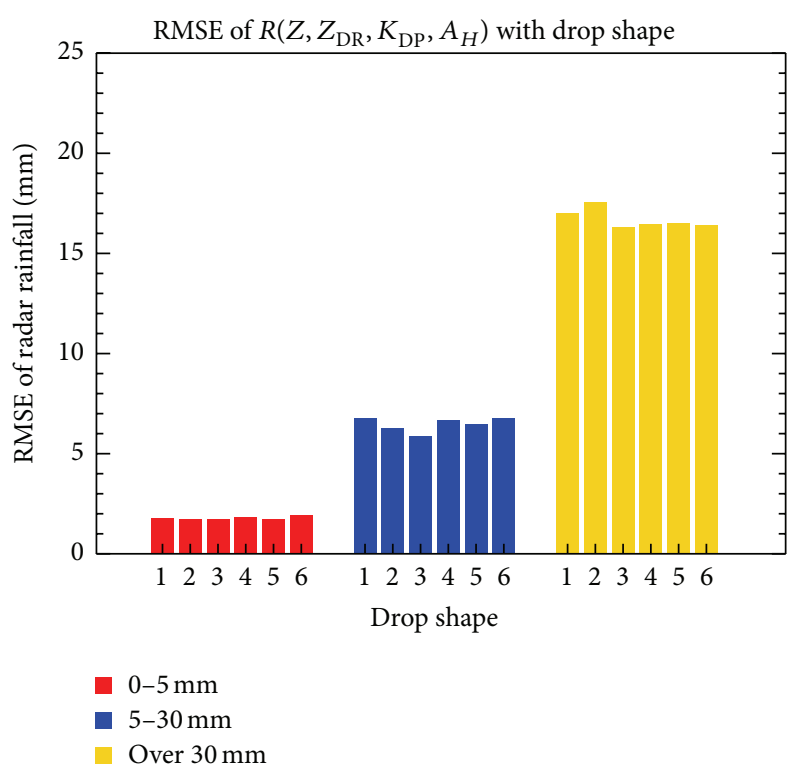

(e)

Figure 10: The RMSEs of (a) $R\left(K_{\mathrm{DP}}\right)$, (b) $R\left(Z, Z_{\mathrm{DP}}\right)$, (c) $R\left(K_{\mathrm{DP}}, Z_{\mathrm{DP}}\right),(\mathrm{d}) R\left(Z, K_{\mathrm{DP}}, A_{H}\right)$, and (e) $R\left(Z, Z_{\mathrm{DP}}, K_{\mathrm{DP}}, A_{H}\right)$ with raindrop axis ratio relations in the three rainfall categories. 
rain, medium rain, and high rainfall regimes, respectively. $R\left(Z, Z_{\mathrm{DR}}, K_{\mathrm{DP}}, A_{H}\right)$ and $R\left(Z, K_{\mathrm{DP}}, A_{H}\right)$ showed relatively good performance in all rainfall regimes. The combination of $R\left(Z, Z_{\mathrm{DR}}\right), R\left(K_{\mathrm{DP}}, Z_{\mathrm{DR}}\right)$, and $R\left(K_{\mathrm{DP}}\right)$ with rainfall intensity would be an optimum rainfall algorithm if the reference of rainfall would be defined correctly. Regardless of rainfall intensity, $R\left(Z, Z_{\mathrm{DR}}, K_{\mathrm{DP}}, A_{H}\right)$ and $R\left(Z, K_{\mathrm{DP}}, A_{H}\right)$ obtained by assuming DS3 can be used as a representative rainfall relation without consideration of rainfall intensity regime. Particularly if the qualified $Z_{\mathrm{DR}}$ is not available, $R\left(Z, K_{\mathrm{DP}}, A_{H}\right)$ with DS3 drop shape assumption can be used as an optimum rainfall relation in Korea.

\section{Conflict of Interests}

The authors declare that they have no conflict of interests regarding the publication of this paper.

\section{Acknowledgments}

The authors acknowledge providing radar data, weather chart, and AWS data for this work from the Ministry of Land, Infrastructure, Transport and Korea Meteorological Administration. The authors also acknowledge providing codes for scattering simulation from Professor V. N. Bringi at Colorado State University. This work was funded by the Korea Meteorological Industry Promotion Agency under Grant KMIPA 2015-1050.

\section{References}

[1] E. Campos and I. Zawadzki, "Instrumental uncertainties in Z$R$ relations," Journal of Applied Meteorology, vol. 39, no. 7, pp. 1088-1102, 2000.

[2] C.-H. You, D.-I. Lee, S.-M. Jang et al., "Characteristics of rainfall systems accompanied with Changma front at Chujado in Korea," Asia-Pacific Journal of Atmospheric Sciences, vol. 46, no. 1, pp. 41-51, 2010.

[3] P. C. Waterman, "Symmetry, unitarity, and geometry in electromagnetic scattering," Physical Review D, vol. 3, no. 4, pp. 825839, 1971.

[4] M. I. Mishchenko, L. D. Travis, and D. W. Mackowski, “T-matrix computations of light scattering by nonspherical particles: a review," Journal of Quantitative Spectroscopy and Radiative Transfer, vol. 55, no. 5, pp. 535-575, 1996.

[5] H. R. Pruppacher and K. V. Beard, "A wind tunnel investigation of the internal circulation and shape of water drops falling at terminal velocity in air," Quarterly Journal of the Royal Meteorological Society, vol. 96, no. 408, pp. 247-256, 1970.

[6] D. C. Blanchard, "The behavior of water drops at terminal velocity in air," EOS, vol. 31, no. 6, pp. 836-842, 1950.

[7] G.-J. Huang, V. N. Bringi, M. Schonhuber et al., "Drop shape and canting angle distributions in rain from 2-D video disdrometer," in Proceedings of the 33rd Conference on Radar Meteorology, Extended Abstract P.8A.8, Cairns, Australia, August 2007.

[8] M. Thurai, V. N. Bringi, and W. A. Petersen, "Rain microstructure retrievals using 2-D video disdrometer and C-band polarimetric radar," Advances in Geosciences, vol. 20, pp. 13-18, 2009.

[9] K. V. Beard and C. Chuang, "A new model for the equilibrium shape of raindrops," Journal of the Atmospheric Sciences, vol. 44, pp. 1509-1524, 1987.
[10] K. Andsager, K. V. Beard, and N. S. Laird, "A laboratory study of oscillations and axis ratios for large raindrops," Journal of the Atmospheric Sciences, vol. 55, pp. 208-226, 1999.

[11] J. W. Wilson and E. A. Brandes, "Radar measurement of rainfall-a summary," Bulletin American Meteorological Society, vol. 60, no. 9, pp. 1048-1058, 1979.

[12] P. M. Austin, "Relation between measured radar reflectivity and surface rainfall," Monthly Weather Review, vol. 115, no. 5, pp. 1053-1070, 1987.

[13] J. Vivekanandan, D. S. Zrnic, S. M. Ellis, R. Oye, A. V. Ryzhkov, and J. Straka, "Cloud microphysics retrieval using S-band dualpolarization radar measurements," Bulletin of the American Meteorological Society, vol. 80, no. 3, pp. 381-388, 1999.

[14] A. V. Ryzhkov and D. S. Zrnic, "Discrimination between rain and snow with a polarimetric radar," Journal of Applied Meteorology, vol. 37, no. 10, pp. 1228-1240, 1998.

[15] S. E. Giangrande and A. V. Ryzhkov, "Estimation of rainfall based on the results of polarimetric echo classification," Journal of Applied Meteorology and Climatology, vol. 47, no. 9, pp. 24452462, 2008.

[16] A. V. Ryzhkov and D. S. Zrnić, "Assessment of rainfall measurement that uses specific differential phase," Journal of Applied Meteorology, vol. 35, no. 11, pp. 2080-2090, 1996.

[17] P. T. May, T. D. Keenan, D. S. Zrnić, L. D. Carey, and S. A. Rutledge, "Polarimetric radar measurements of tropical rain at a 5-cm wavelength," Journal of Applied Meteorology, vol. 38, no. 6, pp. 750-765, 1999.

[18] V. N. Bringi and V. Chandrasekar, "The polarimetric basis for characterizing precipitation," in Polarimetric Doppler Weather Radar: Principles and Applications, pp. 378-533, Cambridge University Press, Cambridge, UK, 2001.

[19] E. A. Brandes, G. Zhang, and J. Vivekanandan, "Experiments in rainfall estimation with a polarimetric radar in a subtropical environment," Journal of Applied Meteorology, vol. 41, no. 6, pp. 674-685, 2002.

[20] A. V. Ryzhkov, T. J. Schuur, D. W. Burgess, P. L. Heinselman, S. E. Giangrande, and D. S. Zrnic, "The joint polarization experiment: polarimetric rainfall measurements and hydrometeor classification," Bulletin of the American Meteorological Society, vol. 86, no. 6, pp. 809-824, 2005.

[21] A. V. Ryzhkov, S. E. Giangrande, and T. J. Schuur, "Rainfall estimation with a polarimetric prototype of WSR-88D," Journal of Applied Meteorology, vol. 44, no. 4, pp. 502-515, 2005.

[22] R. Cifelli, V. Chandrasekar, S. Lim, P. C. Kennedy, Y. Wang, and S. A. Rutledge, "A new dual-polarization radar rainfall algorithm: application in Colorado precipitation events," Journal of Atmospheric and Oceanic Technology, vol. 28, no. 3, pp. 352-364, 2011.

[23] A. Ryzhkov, M. Diederich, P. Zhang, and C. Simmer, "Potential utilization of specific attenuation for rainfall estimation, mitigation of partial beam blockage, and radar networking," Journal of Atmospheric and Oceanic Technology, vol. 31, no. 3, pp. 599-619, 2014.

[24] C.-H. You, M.-Y. Kang, D.-I. Lee, and H. Uyeda, "Rainfall estimation by S-band polarimetric radar in Korea. Part I: preprocessing and preliminary results," Meteorological Applications, vol. 21, no. 4, pp. 975-983, 2014.

[25] C.-H. You, D.-I. Lee, and M.-Y. Kang, "Rainfall estimation using specific differential phase for the first operational polarimetric radar in Korea," Advances in Meteorology, vol. 2014, Article ID 413717, 10 pages, 2014. 
[26] V. N. Bringi, V. Chandrasekar, J. Hubbert, E. Gorgucci, W. L. Randeu, and M. Schoenhuber, "Raindrop size distribution in different climatic regimes from disdrometer and dual-polarized radar analysis," Journal of the Atmospheric Sciences, vol. 60, no. 2, pp. 354-365, 2003.

[27] E. A. Brandes, G. Zhang, and J. Vivekanandan, "Experiments in rainfall estimation with a polarimetric radar in a subtropical environment," Journal of Applied Meteorology, vol. 41, no. 6, pp. 674-685, 2002.

[28] K. V. Beard and R. J. Kubesh, "Laboratory measurements of small raindrop distortion. Part 2: oscillation frequencies and modes," Journal of the Atmospheric Sciences, vol. 48, no. 20, pp. 2245-2264, 1991.

[29] M. Thurai, G. J. Huang, V. N. Bringi, W. L. Randeu, and M. Schönhuber, "Drop shapes, model comparisons, and calculations of polarimetric radar parameters in rain," Journal of Atmospheric and Oceanic Technology, vol. 24, no. 6, pp. 10191032, 2007.

[30] J. W. F. Goddard, K. L. Morgan, A. Illingworth, and H. Sauvageot, "Dual-wavelength polarization measurements in precipitation using the CAMRA and Rabelias radars," in Proceedings of the 27th Conference on Radar Meteorology, pp. 196198, American Meteorology Society, Vail, Colo, USA, 1995.

[31] A. V. Ryzhkov, D. S. Zrnic, J. C. Hubbert, V. N. Bringi, J. Vivekanandan, and E. A. Brandes, "Polarimetric radar observations and interpretation of co-cross-polar correlation coefficients," Journal of Atmospheric and Oceanic Technology, vol. 19, no. 3, pp. 340-354, 2002.

[32] S. Y. Matrosov, K. A. Clark, B. E. Martner, and A. Tokay, "X-band polarimetric radar measurements of rainfall," Journal of Applied Meteorology, vol. 41, no. 9, pp. 941-952, 2002.

[33] G.-J. Huang, V. N. Bringi, and M. Thurai, "Orientation angle distributions of drops after an $80-\mathrm{m}$ fall using a $2 \mathrm{D}$ video disdrometer," Journal of Atmospheric and Oceanic Technology, vol. 25, no. 9, pp. 1717-1723, 2008.

[34] R. Meneghini and K. Nakamura, "Range profiling of the rain rate by an airborne weather radar," Remote Sensing of Environment, vol. 31, no. 3, pp. 193-209, 1990.

[35] V. N. Bringi, V. Chandrasekar, N. Balakrishnan, and D. S. Zrnić, "An examination of propagation effects in rainfall on polarimetric variables at microwave frequencies," Journal of Atmospheric and Oceanic Technology, vol. 7, no. 6, pp. 829-840, 1990.

[36] J. Testud, E. L. Bouar, E. Obligis, and M. Ali-Mehenni, “The rain profiling algorithm applied to polarimetric weather radar," Journal of Atmospheric and Oceanic Technology, vol. 17, no. 3, pp. 332-356, 2000. 

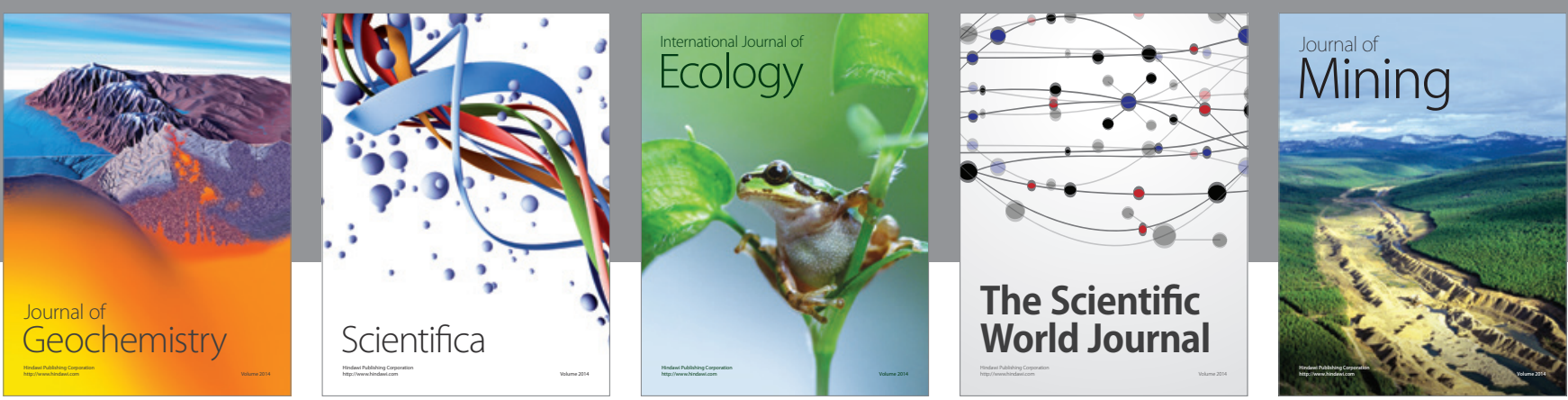

The Scientific World Journal
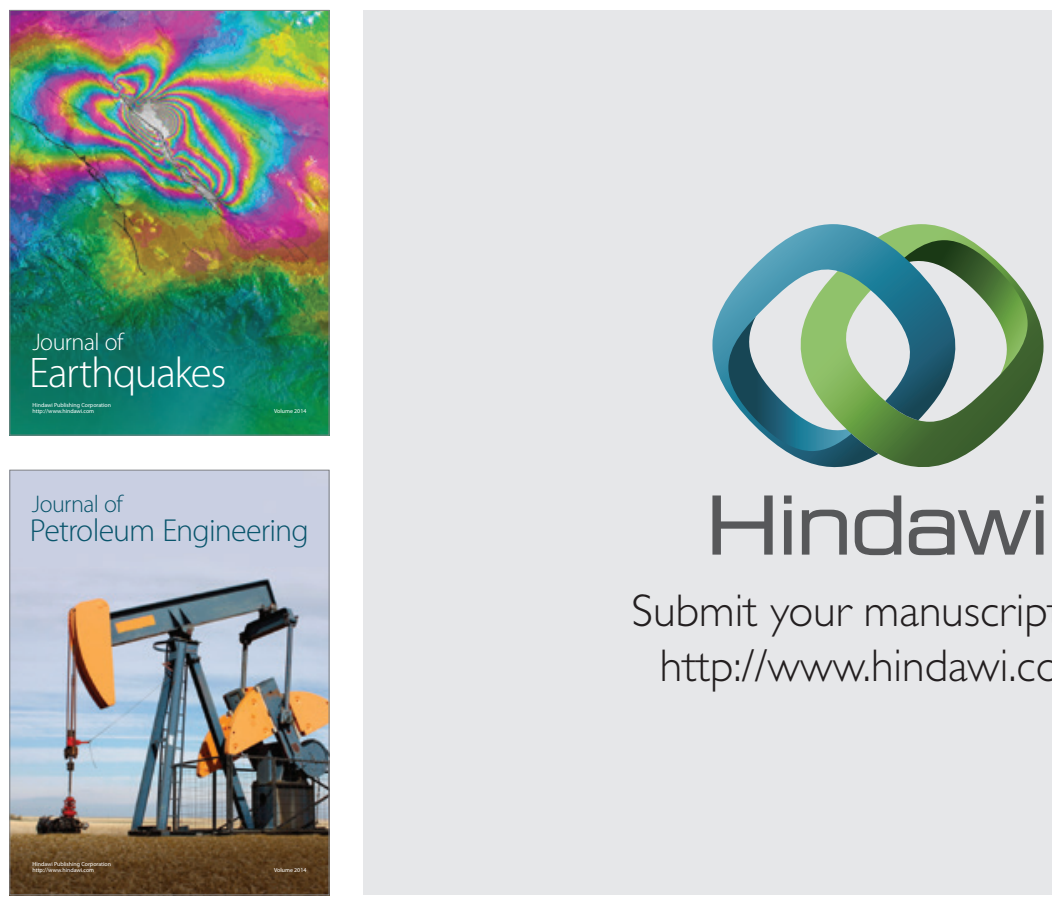

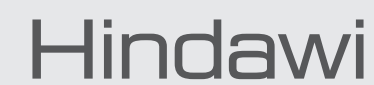

Submit your manuscripts at

http://www.hindawi.com
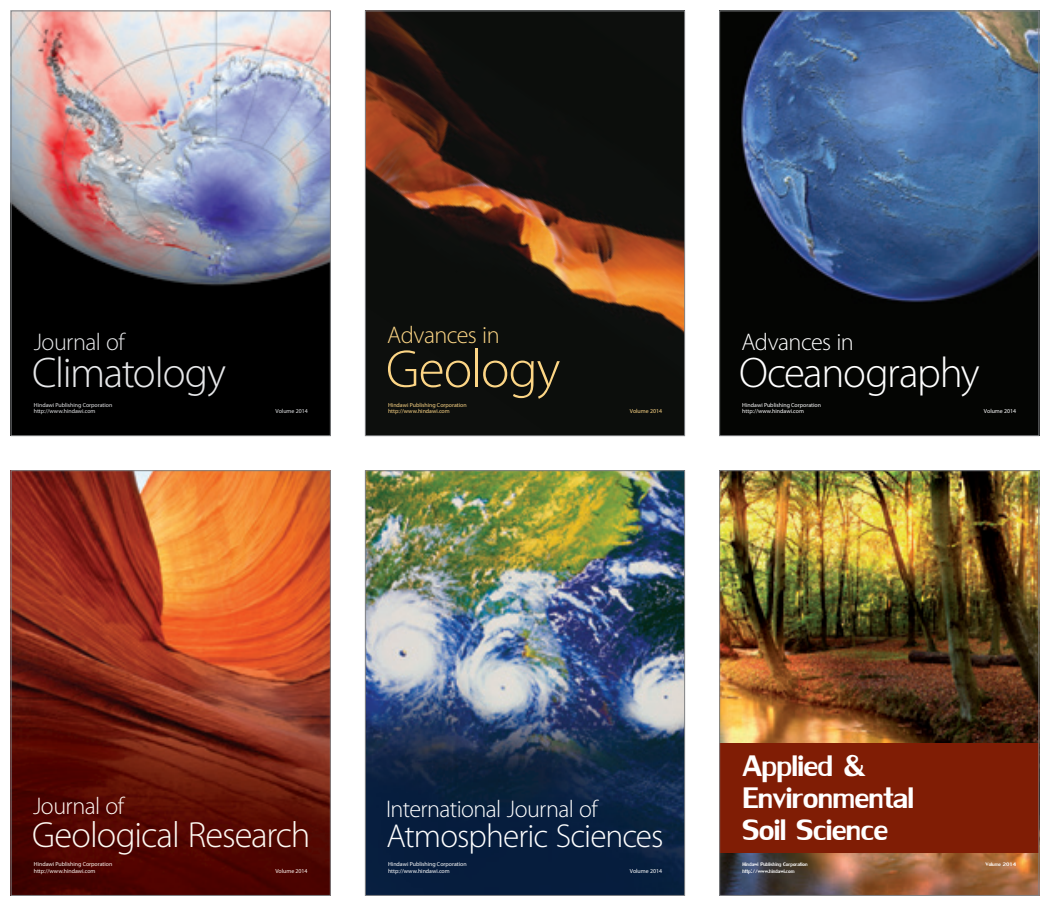
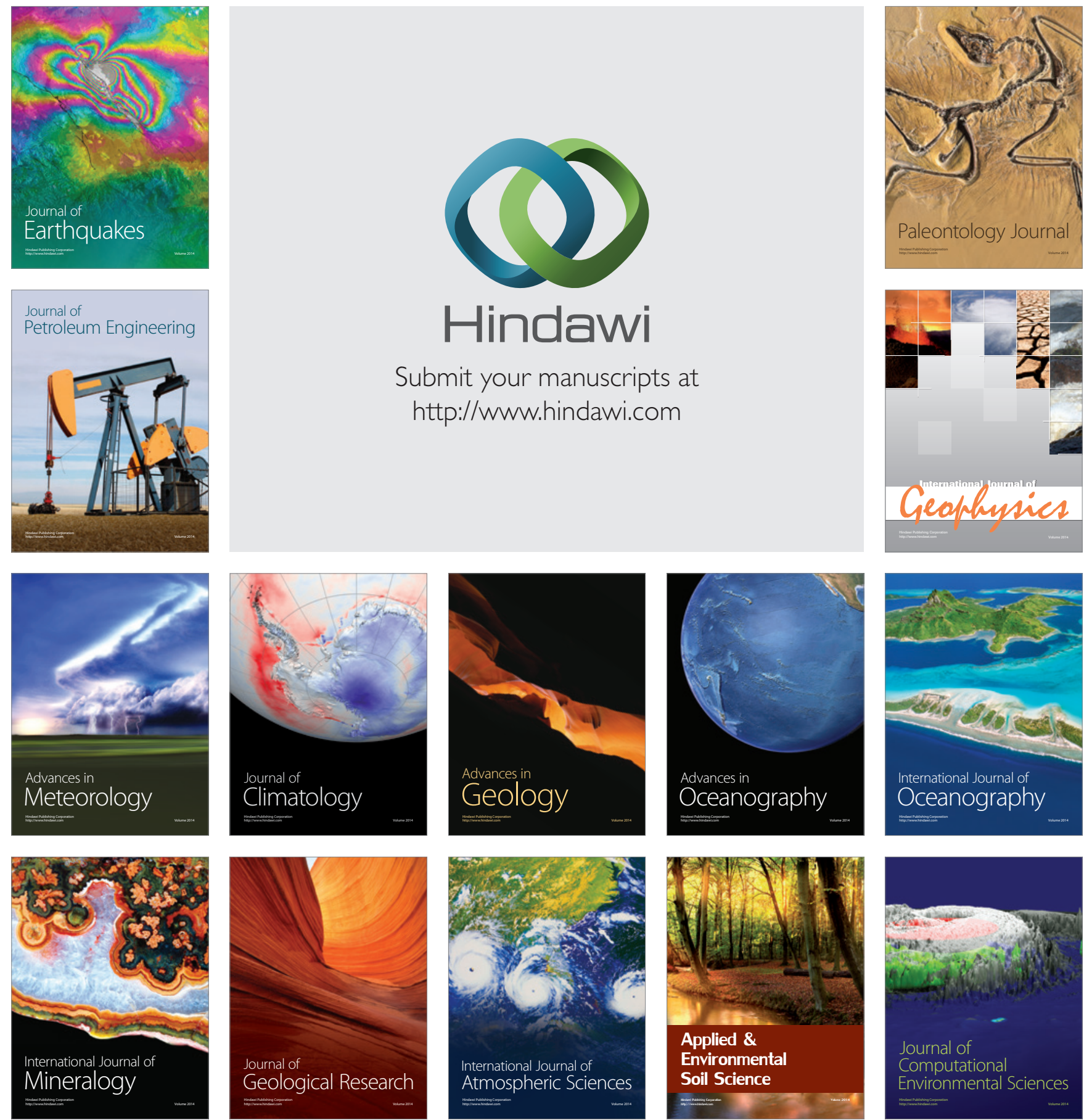